\title{
Effects of Cannabidiol on Exercise Physiology and Bioenergetics: A Randomised Controlled Pilot Trial
}

\author{
Ayshe Sahinovic 1,2,3* , Christopher Irwin ${ }^{4,5}$, Peter T. Doohan ${ }^{1,2,3}$, Richard C. Kevin ${ }^{1,2,3}$, Amanda J. Cox 6 , \\ Namson S. Lau ${ }^{7,8,9}$, Ben Desbrow ${ }^{4,5}$, Nathan A. Johnson ${ }^{9}$, Angelo Sabag ${ }^{10}$, Matthew Hislop ${ }^{11}$, Paul S. Haber ${ }^{9,12}$, \\ lain S. McGregor ${ }^{1,2,3}$ and Danielle McCartney ${ }^{1,2,3}$
}

\begin{abstract}
Background: Cannabidiol (CBD) has demonstrated anti-inflammatory, analgesic, anxiolytic and neuroprotective effects that have the potential to benefit athletes. This pilot study investigated the effects of acute, oral CBD treatment on physiological and psychological responses to aerobic exercise to determine its practical utility within the sporting context.

Methods: On two occasions, nine endurance-trained males (mean $\pm \mathrm{SD} \vee \mathrm{O}_{2 \mathrm{max}}: 57.4 \pm 4.0 \mathrm{~mL} \cdot \mathrm{min}^{-1} \cdot \mathrm{kg}^{-1}$ ) ran for 60 min at a fixed intensity $\left(70 \% \mathrm{VO}_{2 \text { max }}\right)(R \cup N 1)$ before completing an incremental run to exhaustion (RUN 2). Participants received CBD (300 mg; oral) or placebo $1.5 \mathrm{~h}$ before exercise in a randomised, double-blind design. Respiratory gases $\left(\mathrm{VO}_{2}\right)$, respiratory exchange ratio $(\mathrm{RER})$, heart rate $(\mathrm{HR})$, blood glucose $(\mathrm{BG})$ and lactate $(\mathrm{BL})$ concentrations, and ratings of perceived exertion (RPE) and pleasure-displeasure were measured at three timepoints (T1-3) during RUN 1. $V_{\mathrm{O}_{\text {max }}} \mathrm{RER}_{\text {max }}, H R_{\max }$ and time to exhaustion (TTE) were recorded during RUN 2. Venous blood was drawn at Baseline, Pre- and Post-RUN 1, Post-RUN 2 and $1 \mathrm{~h}$ Post-RUN 2. Data were synthesised using Cohen's $d_{z}$ effect sizes and 85\% confidence intervals (Cls). Effects were considered worthy of further investigation if the $85 \% \mathrm{Cl}$ included \pm 0.5 but not zero.

Results: $C B D$ appeared to increase $\mathrm{VO}_{2}\left(\mathrm{~T} 2:+38 \pm 48 \mathrm{~mL} \cdot \mathrm{min}^{-1}, d_{z}: 0.25-1.35\right)$, ratings of pleasure $\left(T 1:+0.7 \pm 0.9, d_{z}\right.$ : $\left.0.22-1.32 ; T 2:+0.8 \pm 1.1, d_{z}: 0.17-1.25\right)$ and $B L\left(T 2:+3.3 \pm 6.4 \mathrm{mmol} \cdot \mathrm{L}^{-1}, d_{z}:>0.00-1.03\right)$ during RUN 1 compared to placebo. No differences in $\mathrm{HR}, \mathrm{RPE}, \mathrm{BG}$ or RER were observed between treatments. CBD appeared to increase $\mathrm{VO}_{2 \max }$ $\left(+119 \pm 206 \mathrm{~mL} \cdot \mathrm{min}^{-1}, d_{z}: 0.06-1.10\right)$ and RER $\max \left(+0.04 \pm 0.05 d_{z}: 0.24-1.34\right)$ during RUN 2 compared to placebo. No differences in TTE or $\mathrm{HR}_{\max }$ were observed between treatments. Exercise increased serum interleukin (IL)-6, IL-1 $\beta$, tumour necrosis factor-a, lipopolysaccharide and myoglobin concentrations (i.e. Baseline vs. Post-RUN 1, Post-RUN 2 and/or 1-h Post-RUN 2, p's <0.05). However, the changes were small, making it difficult to reliably evaluate the effect of $C B D$, where an effect appeared to be present. Plasma concentrations of the endogenous cannabinoid, anandamide (AEA), increased Post-RUN 1 and Post-RUN 2, relative to Baseline and Pre-RUN 1 ( $p$ 's $<0.05$ ). CBD appeared to reduce AEA concentrations Post-RUN 2, compared to placebo $\left(-0.95 \pm 0.64 \mathrm{pmol} \cdot \mathrm{mL}^{-1}, d_{z}:-2.19,-0.79\right)$.
\end{abstract}

Conclusion: CBD appears to alter some key physiological and psychological responses to aerobic exercise without impairing performance. Larger studies are required to confirm and better understand these preliminary findings.

\footnotetext{
*Correspondence: ayshe.sahinovic@sydney.edu.au

${ }^{1}$ Lambert Initiative for Cannabinoid Therapeutics, The University

of Sydney, Sydney, NSW, Australia

Full list of author information is available at the end of the article
}

\section{Springer Open}

(c) The Author(s) 2022. Open Access This article is licensed under a Creative Commons Attribution 4.0 International License, which permits use, sharing, adaptation, distribution and reproduction in any medium or format, as long as you give appropriate credit to the original author(s) and the source, provide a link to the Creative Commons licence, and indicate if changes were made. The images or other third party material in this article are included in the article's Creative Commons licence, unless indicated otherwise in a credit line to the material. If material is not included in the article's Creative Commons licence and your intended use is not permitted by statutory regulation or exceeds the permitted use, you will need to obtain permission directly from the copyright holder. To view a copy of this licence, visit http://creativecommons.org/licenses/by/4.0/. 
Trial Registration This investigation was approved by the Sydney Local Health District's Human Research Ethics Committee (2020/ETH00226) and registered with the Australia and New Zealand Clinical Trials Registry (ACTRN12620000941965).

Keywords: Cannabis, Cannabinoid, Cannabidiol, CBD, Sport, Supplement

\section{Key Points}

- CBD (300 mg; oral) appears to alter physiological and psychological responses to aerobic exercise.

- The effects of CBD on submaximal $\left(\mathrm{VO}_{2}\right)$ and maximal $\left(\mathrm{VO}_{2 \max }\right)$ oxygen consumption, feelings of pleasure during exercise, and exercise-induced inflammation are worthy of further investigation.

- CBD does not appear to impair aerobic exercise performance and could, therefore, have utility within the sporting context.

\section{Introduction}

Cannabidiol (CBD) is a non-intoxicating, plant-derived cannabinoid that has demonstrated considerable therapeutic potential [1]. CBD has well-established anticonvulsant effects [2-4], with the Food and Drug Administration (FDA) recently approving the oral CBD solution, Epidiolex ${ }^{\circledR}$, for the treatment of intractable paediatric epilepsy [5]. Early-stage clinical trials have also demonstrated anxiolytic $[6,7]$ and antipsychotic $[8,9]$ effects. These effects are typically observed at oral doses of 300-1500 mg CBD [10], although acute doses up to $6000 \mathrm{mg}$ also appear to be safe and well-tolerated in humans, albeit with occasional mild side effects (e.g. diarrhoea, nausea, headache) $[11,12]$.

Alongside its emergent clinical use [13], interest in CBD has increased among general (non-clinical) populations [14, 15], including athletes [16]. While healthy individuals are usually ineligible to access regulated, prescription CBD (e.g. Epidiolex ${ }^{\circledR}$ ), a wide range of lowdose "nutraceuticals" (e.g. oils, capsules, topicals and edibles typically containing between $\sim 5$ and $150 \mathrm{mg}$ CBD.dose ${ }^{-1}$ ), including some products marketed specifically to athletes (e.g. $\operatorname{cbdMD}^{\mathrm{TM}}$, fourfivecbd ${ }^{\mathrm{TM}}$ ), are readily available over-the-counter in certain countries (e.g. UK, Canada, USA) [17]. Within the context of elite sports, the use of CBD has been further facilitated by its recent removal from the World Anti-Doping Agency's "Prohibited List" [18]. In fact, $26 \%$ of British professional rugby players surveyed in a recent study $(n=517 ; 39 \%$ of those aged $\geq 28$ years) reported either currently using, or having previously used, CBD [16]. The most common reasons for use were to enhance recovery (80\%), improve sleep (78\%), reduce anxiety (32\%), and for "other" medical purposes (14\%; e.g. concussion) [16].

Despite its growing popularity [16], only two interventional studies, both randomised, double-blind, placebocontrolled crossover trials, have so far investigated the effects of CBD on outcomes relevant to athletic performance. The first found no effect of CBD $\left(150 \mathrm{mg} \cdot \mathrm{d}^{-1}\right.$ for 3 days) on non-invasive measures of muscle damage following eccentric exercise [19]. The second found CBD (60 mg; acute) decreased blood serum concentrations of creatine kinase and myoglobin, and increased onerepetition maximum back squat performance $72 \mathrm{~h}$, but not 24 or $48 \mathrm{~h}$ following resistance exercise [20]. In any case, a recent review of preclinical studies and clinical trials (involving non-athlete populations) outlined the potential for CBD to exert anti-inflammatory, analgesic, anxiolytic and neuroprotective effects that could have utility in treating inflammatory pain (e.g. delayed onset muscle soreness, injuries), head injuries (e.g. concussion) and sports performance anxiety in athletes [21]. Of course, if CBD is to be used within the sporting context, it is important to understand how it influences key physiological and psychological responses during exercise, particularly given its complex pharmacology [22].

The current randomised, placebo-controlled exploratory pilot trial investigated the effects of acute, oral CBD treatment on physiological and psychological responses to submaximal and exhaustive running exercise in a small sample of endurance-trained males. It should be noted that, as a pilot study, this investigation was not designed nor formally powered to assess "effect" [23]. Rather, its intent was to gain a preliminary understanding of CBD's effects on exercise physiology and to determine whether these are worthy of further investigation in larger, fully powered trials.

\section{Methods}

This investigation was approved by the Sydney Local Health District's Human Research Ethics Committee (2020/ETH00226), registered with the Australia and New Zealand Clinical Trials Registry (ACTRN12620000941965) and conducted at the Charles Perkins Centre-Royal Prince Alfred Hospital Clinic, Sydney, Australia, in accordance with Good Clinical Practice guidelines, the Declaration of Helsinki (1983) and local regulations. 


\section{Study Design}

Participants completed two treatment sessions involving the oral administration of CBD (300 $\mathrm{mg})$ or a placebo in a randomised, double-blind, crossover design. Sessions were separated by a washout period $\geq 7$ days on the basis that orally administered CBD $(\sim 300 \mathrm{mg})$ has been reported to have a half-life of $\sim 24 \mathrm{~h}$ [24]. Individuals were instructed to maintain their usual diet and exercise patterns and avoid using cannabis and cannabinoids throughout their participation.

\section{Randomisation and Blinding}

Participants were assigned to one of two possible treatment orders (CBD-Placebo or Placebo-CBD) in a 1:1 ratio by a blinded physician using a pre-populated randomisation schedule. This schedule was generated in two balanced blocks of four and one balanced block of two by an independent researcher, using an online random number generator (www.randomizer.org). Only this individual and pharmacists dispensing the treatments could access the randomisation schedule and neither had any contact with participants.

\section{Treatments}

The investigational product (GD Cann ${ }^{\circledR}-\mathrm{C}$; GD Pharma Pty Ltd, Norwood, South Australia, Australia) was an oral formulation of synthetic CBD $\left(100 \mathrm{mg} \cdot \mathrm{mL}^{-1}\right)$ in medium chain triglyceride (MCT) oil; the placebo was an equivalent volume of MCT oil, only. Neither product contained any other cannabinoids (including THC) or cannabis constituents (e.g., flavonoids, monoterpenes, sesquiterpenes) or differed noticeably in visual appearance or smell. Pharmacists dispensed the treatments into $5.0 \mathrm{~mL}$ syringes that carried no "treatment-identifying" information (e.g. letters, numbers) at the beginning of each session. The dose (300 $\mathrm{mg} \mathrm{CBD;} 3.0 \mathrm{~mL}$ ) was selected on the basis that it is the smallest amount to have, so far, reliably demonstrated clinically relevant effects in humans [11].

\section{Participant Characteristics}

Healthy males aged between 18 and 45 years who had not used cannabis or cannabinoids in the previous three months (as confirmed by a negative urine drug screen [UDS]) and reported running an average of $\geq 40 \mathrm{~km} \cdot \mathrm{wk}^{-1}$ were recruited via word-of-mouth and using a general advertisement distributed to local running clubs. The full eligibility criteria are available in Additional file 1. A target sample size of $n=10$ was selected with consideration for practical factors such as time, cost and resource allocation, rather than using formal statistical techniques, as this was an exploratory pilot study [25].

\section{Participant Screening}

Volunteers completed a short telephone interview before scheduling a face-to-face screening visit, during which they were informed of the study requirements and risks and provided written informed consent. Eligibility was then assessed by an investigator and physician as per the criteria in Additional file 1. Finally, eligible participants performed an incremental treadmill test to determine maximal oxygen consumption $\left(\mathrm{VO}_{2 \max }\right)$ and to become familiar with trial procedures. The protocol used during the initial $\mathrm{VO}_{2 \max }$ test was identical to that used during the experiment ("Incremental Exercise (RUN 2)" section), except respiratory gases were sampled continuously throughout. The average rate of oxygen consumption $\left(\mathrm{VO}_{2}\right)$ over the final $30 \mathrm{~s}$ of each (completed) increment was also calculated, and the linear relationship between $\mathrm{VO}_{2}$ and treadmill gradient determined, to set the exercise intensity during subsequent sessions.

\section{Experimental Procedures}

The experimental procedures and timelines are summarised in Fig. 1.

\section{Standardisation Procedures}

Participants were instructed to: (1) abstain from alcohol (>24 h) and caffeine (>12 h); (2) avoid moderate to strenuous exercise ( $>24 \mathrm{~h})$; (3) avoid anti-inflammatory medication (>24 h); (4) keep a diet record (24 h); (5) consume a pre-packaged standardised evening meal $\left(\sim 60 \mathrm{~kJ} \cdot \mathrm{kg}^{-1} ; \sim 2.0 \mathrm{~g} \cdot \mathrm{kg}^{-1}\right.$ carbohydrate $\left.[\mathrm{CHO}]\right) ;(6)$ fast overnight ( $\sim 10 \mathrm{~h})$; (7) spend $\geq 8 \mathrm{~h}$ in bed; and (8) collect a first-morning urine sample and consume $500 \mathrm{~mL}$ of water before presenting to the laboratory. Individuals received a copy of their pre-trial diet record after the first session and were instructed to replicate their behaviour before their second visit.

\section{Trial Procedures}

Participants arrived at the laboratory in a fasted state at 08:30 AM on the morning of each treatment session where they verbally acknowledged compliance to the standardisation procedures and completed a UDS to verify cannabis abstinence (Drug Check ${ }^{\circledR}$ NxStep OnSite Urine Drug Test). The first-morning urine sample was also analysed to determine urine-specific gravity ( $\mathrm{U}_{\mathrm{SG}}$; Palette Digital Refractometer, ATAGO, USA). If $\mathrm{U}_{\mathrm{SG}}$ was $>1.024$, likely indicating hypohydration [26], a second sample was collected and analysed (all had $\mathrm{U}_{\mathrm{SG}}$ values $\leq 1.024)$. 


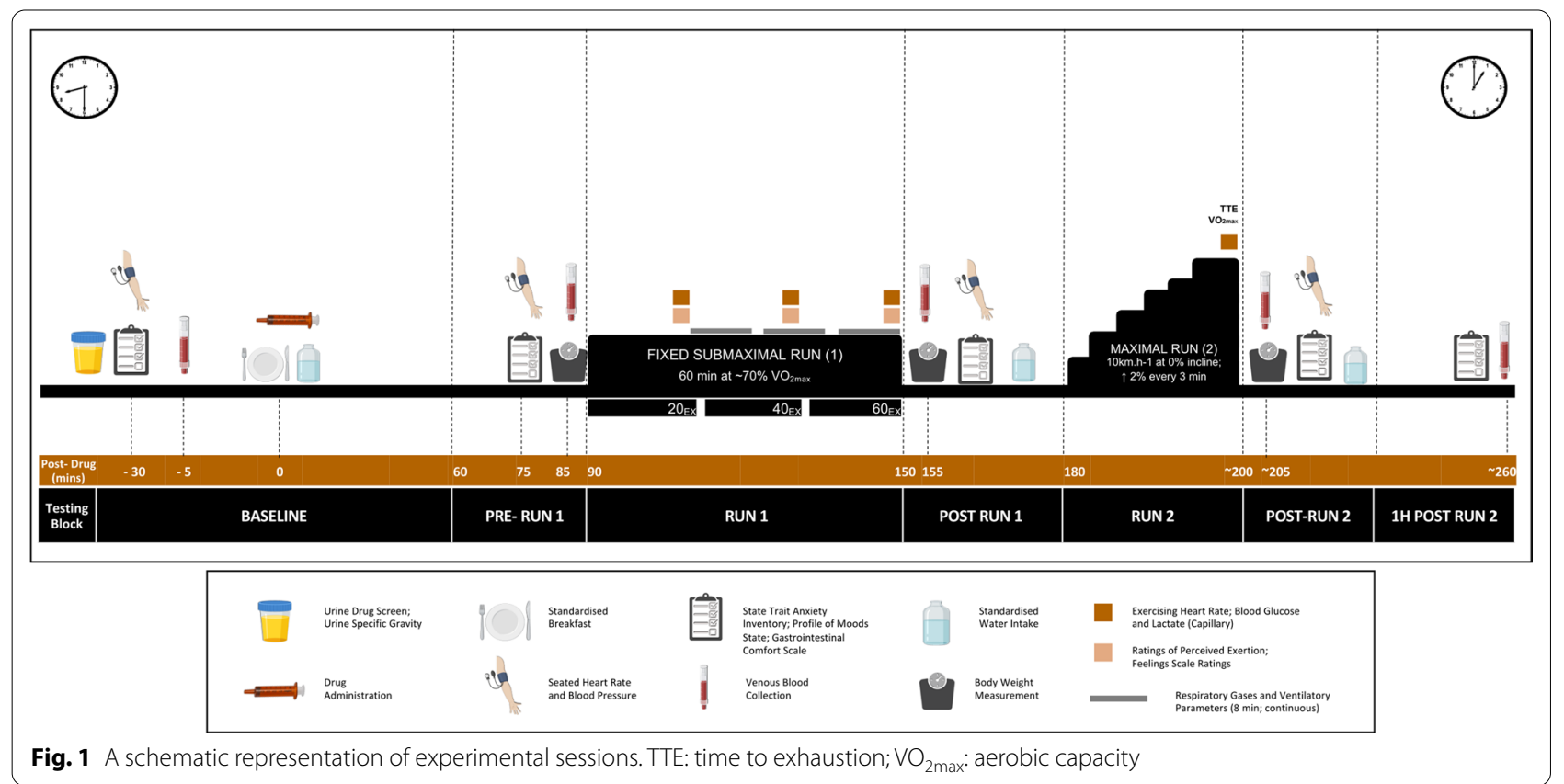

Each session involved seven consecutive blocks of testing: Baseline (pre-treatment), Pre-RUN 1 (+60-90 min post-treatment), RUN 1 (+90-150 min), Post-RUN 1 (+155-170 min), RUN 2 (+180- approx. $200 \mathrm{~min}$ ), Post-RUN 2 (approx. $+205-220 \mathrm{~min}$ ) and $1 \mathrm{~h}$ Post-RUN 2 (approx. +220-260 min). The assessments completed during each block are summarised in Fig. 1 and detailed.

Baseline tests consisted of resting heart rate (HR) and blood pressure (BP) measurements, the completion of the short-form State-Trait Anxiety Inventory (STAI-S), the short-form Profile of Mood States (POMS), and gastrointestinal (GI) comfort questionnaires, and sampling of venous blood. Thereafter, participants received a standardised breakfast consisting of raisin toast (two slices) (TipTop ${ }^{\circledR}$ ) and up to $30 \mathrm{~g}$ of raspberry jam (Cottee's ${ }^{\circledR}$ ), $20 \mathrm{~g}$ of margarine (Flora ${ }^{\circledR}$ Proactive Original) and $500 \mathrm{~mL}$ of water (as preferred); individual intakes were recorded and replicated across sessions. Treatments were selfadministered (via oral ingestion) following the consumption of breakfast and a high-strength mint (Fisherman's Friend $^{\circledR}$ ) designed to mask any differences in flavour [27]. Exercise was performed on a motorised treadmill (Trackmaster $^{\circledR}$ TMX428CP) in a thermoneutral laboratory as described in "Submaximal Exercise ("RUN 1")" section and "Incremental Exercise ("RUN 2")" section. Participants were not permitted to consume fluid during exercise but received up to $500 \mathrm{~mL}$ of water on completion of the Post-RUN 1 and 2 assessments; again, individual intakes were recorded and replicated across sessions.
At the end of each treatment session, participants completed an adverse event (AE) checklist and indicated which treatment they thought they had received and their level of confidence in their guess (on a 4-point Likert scale; $1=$ "not at all" to $4=$ "extremely").

\section{Submaximal Exercise ("RUN 1")}

Submaximal exercise (RUN 1) began 90 min posttreatment. Participants ran for $60 \mathrm{~min}$ at a fixed speed $\left(10 \mathrm{~km} \cdot \mathrm{h}^{-1}\right)$ and individualised gradient designed to elicit an intensity of $70 \% \mathrm{VO}_{2 \max }$. Respiratory gases were sampled continuously between 24-32 (24 $\left.4_{\mathrm{EX}}\right), 37-45$ (37 $\mathrm{EX}$ ) and 50-58 $\left(50_{\mathrm{EX}}\right) \mathrm{min}$ of exercise. Measures were collected at precisely the same time to minimise any influence of metabolic drift [28]. HR (Polar H10 HR Sensor), ratings of perceived exertion (RPE) on the Borg scale (6-20) [29], ratings of affect (i.e. pleasure-displeasure) on the Feelings Scale $(-5=$ "feeling very bad" to $+5=$ "feeling very good") [30], and finger prick blood lactate (BL) and glucose (BG) concentrations (in singlicate) (Edge ${ }^{\circledR}$ Blood Lactate Monitoring System; Accu-Check ${ }^{\circledR}$ Performa Meter) were also measured at $20\left(20_{\mathrm{EX}}\right), 40\left(40_{\mathrm{EX}}\right)$ and 60 $\left(60_{\mathrm{EX}}\right)$ minutes.

\section{Incremental Exercise ("RUN 2")}

The incremental exercise test (RUN 2) began $180 \mathrm{~min}$ post-treatment. The test was completed at a fixed speed $\left(10 \mathrm{~km} \cdot \mathrm{h}^{-1}\right)$, with the gradient commencing at $0 \%$ and increasing by $2 \%$ every 3 min until volitional exhaustion. Participants did not receive feedback on elapsed time or 
encouragement during the test. Respiratory gases were sampled during the final $\sim 5 \mathrm{~min}$ of exercise (i.e. from the point at which $\mathrm{HR}$ exceeded $\sim 90 \% \mathrm{HR}_{\max }$, as determined during the initial $\mathrm{VO}_{2 \max }$ test). Time to exhaustion (TTE) and maximum $\mathrm{HR}$ attained $\left(\mathrm{HR}_{\max }\right)$ were recorded.

\section{Data Collection \\ Respiratory Gases}

Respiratory gases were sampled using an Ultima PFX $^{\circledR}$ pulmonary function system (MGC Diagnostics ${ }^{\circledR}$ ) with a PreVent ${ }^{\mathrm{TM}}$ flow pneumotach (MCG Diagnostics ${ }^{\circledR}$ ) and mouthpiece. The flow transducer and gas analysers were calibrated daily. Breath-by-breath measurements of $\mathrm{VO}_{2}$, expired $\mathrm{CO}_{2}\left(\mathrm{VCO}_{2}\right)$, respiratory exchange ratio (RER), respiratory rate $(R R)$, tidal volume $\left(V_{T}\right)$ and minute ventilation $\left(\mathrm{V}_{\mathrm{E}}\right)$ were obtained and averaged across each collection period. $\mathrm{VO}_{2 \max }$ was taken as the highest average $\mathrm{VO}_{2}$ attained over $30 \mathrm{~s} ; \mathrm{VCO}_{2 \max }$ and $\mathrm{RER}_{\text {max }}$ were taken as the average of the aforementioned period.

\section{Sweat Loss}

Nude body weight (BW) was measured Pre- and PostRUN 1 and Post-RUN 2 to estimate sweat loss. Water intake and urinary losses were measured and factored into all estimations.

\section{Resting Blood Pressure (BP)}

Seated BP was measured at Baseline, Pre- and Post-RUN 1, Post-RUN 2 and $1 \mathrm{~h}$ Post-RUN 2 using an automated sphygmomanometer $\left(\mathrm{OMRON}^{\circledR}, \mathrm{M} 2\right.$ Basic). Measurements were taken in duplicate or triplicate if systolic BP values differed by $>15 \mathrm{mmHg}$ and then averaged prior to analysis [31].

\section{Gastrointestinal (GI) Comfort}

GI comfort ("Abdominal Pain", "Nausea”, "Heartburn", "Regurgitation", "Belching", "Bloating" and "Flatulence") was measured at Baseline, Pre- and Post-RUN 1, PostRUN 2 and $1 \mathrm{~h}$ Post-RUN 2 using $100 \mathrm{~mm}$ visual analogue scales (VAS) where $0 \mathrm{~mm}$ represented "not at all" and $100 \mathrm{~mm}$, "extremely".

\section{Subjective Feelings}

State anxiety and mood were measured at Baseline, Preand Post-RUN 1, Post-RUN 2 and 1 h Post-RUN 2 using the short-form STAI-S [32] and short-form POMS [33] as described in Additional file 1.

\section{Blood Sampling and Biomarker Analyses}

Blood was collected into $10 \mathrm{~mL}$ pre-treated EDTA vacutainers and $6 \mathrm{~mL}$ serum vacutainers (VACUETTE ${ }^{\circledR}$, Greiner Bio-One, Kremsmünster, Austria) at Baseline, Pre-RUN 1 (plasma only), Post-RUN 1, Post-RUN 2 and
1 h Post-RUN 2 via a cannula inserted into an antecubital forearm vein. Samples were centrifuged at $2500 \mathrm{RCF}$ for $15 \mathrm{~min}\left(4^{\circ} \mathrm{C}\right)$ after the serum sample had clotted (approx. $15 \mathrm{~min})$. Aliquots of supernatant were stored at $-80{ }^{\circ} \mathrm{C}$ until analysis.

Plasma was thawed and analysed using ultra-high performance liquid tandem mass spectrometry (UHPLCMS/MS) and previously validated methods [34]. Target analytes were $\mathrm{CBD}, 7-\mathrm{COOH}-\mathrm{CBD}, 7-\mathrm{OH}-\mathrm{CBD}, 6-\mathrm{OH}-$ CBD, THC, 11-OH-THC and 11-COOH-THC. The maximum plasma $\mathrm{CBD}$ concentration $\left(C_{\max }\right)$ and time to $C_{\max }\left(T_{\max }\right)$ were estimated for each individual participant; specifically, $C_{\max }$ was taken as the highest concentration of CBD measured in plasma and $T_{\max }$ was taken as the timepoint at which $C_{\max }$ occurred. Plasma anandamide (AEA) concentrations were also determined using UHPLC-MS/MS (see Additional file 1 for methods).

Serum samples were thawed and analysed to determine circulating interleukin (IL)-1 $\beta$, tumour necrosis factor- $\alpha$ (TNF- $\alpha)$, myoglobin (Mb), creatine kinase (CK) and claudin-3 (NBP2-75,328; Novus Biologicals, Centennial, USA) concentrations using commercially available enzyme-linked immunosorbent assay (ELISA) kits (see Additional file 1 for methods). Circulating lipopolysaccharide (LPS) was determined using the limulus amebocyte lysate (LAL) chromogenic endpoint assay (see Additional file 1 for methods).

\section{Next-day Sleep Quality and Muscle Soreness}

Sleep quality $(-5=$ "very poor" to $+5=$ "very good") and muscle soreness $(0=$ "not at all" to $10=$ "extremely") were measured the morning following each treatment session using Likert scales.

\section{Statistical Analyses}

Being exploratory and pilot in nature, the current study was not designed nor formally powered to assess "effect" [25]. Rather, the intent was to gain a preliminary understanding of CBD's effects on exercise physiology and determine whether these are worthy of further investigation in a larger, fully powered trial. As such, data analysis involved the determination of effect sizes and confidence intervals (CIs) (23). Cohen's $d_{\mathrm{z}}$ effect sizes (chosen to facilitate future sample size calculations) were calculated by standardising the mean difference between each placebo and intervention outcome measure against the $\mathrm{SD}$ of change $\left(\mathrm{SD}_{\Delta}\right)$ [35]. The standard error (SE) was then derived using the Hedges \& Olkin approximation adapted for a repeated measures design [36, 37]:

$$
\mathrm{SE}_{\mathrm{d}}=\sqrt{\left(\frac{1}{n}+\frac{d^{2}}{2 n}\right) \times 2 \times(1-R)}
$$


where $\mathrm{SE}_{\mathrm{d}}$ is the SE of Cohen's $d, d$ is Cohen's $d_{\mathrm{z}}, n$ is the sample size and $R$ is the correlation coefficient. $\mathrm{SE}_{\mathrm{d}}$ values were then divided by a factor of $\sqrt{2(1-R)}$ to derive the SE of Cohen's $d_{\mathrm{z}}$ specifically [36, 38], and $85 \%$ CIs were derived via standard methods [39]. Lee, Whitehead, Jacques and Julious [23] recommend using $75 \%$ or $85 \%$ CIs rather than the common $95 \%$ threshold to investigate pilot data. CBD's effects were then interpreted as follows: "uncertain" if the $85 \% \mathrm{CI}$ included zero and \pm 0.5 ; "unlikely affected" if the $85 \% \mathrm{CI}$ included zero but not \pm 0.5 ; and "possibly affected" (i.e. worthy of further investigation) if the $85 \% \mathrm{CI}$ included \pm 0.5 but not zero. Thresholds $( \pm 0.5)$ were selected on the basis that they represent a "moderate" Cohen's $d_{\mathrm{z}}$ effect [39].

Statistical analyses were performed using SPSS Statistics, Version 26.0 (IBM Corp. 2019, Armonk, N.Y., USA). Treatment $\times$ Time repeated-measures analyses of variance (ANOVA) was used to investigate time effects on blood biomarkers (only); that is, on outcomes where an effect of CBD is predicated on an exerciseinduced change. All measures were normally distributed (Shapiro-Wilk test, $p$ 's $>0.05$ ). Where assumptions of sphericity (Mauchly's test) were violated, the Greenhouse-Geisser correction was applied. Paired $t$-tests were used to conduct post hoc comparisons on significant time effects (at the least significant difference) and compare standardisation outcomes across treatment sessions. Statistical significance was accepted as $p<0.05$. Data are reported as Mean $\pm \mathrm{SD}$, unless otherwise stated.

\section{Results}

Participant Characteristics and Standardisation Procedures Ten participants were recruited and randomised between August 2020 and October 2020 (Fig. 2). One participant withdrew during their second session $(<5 \mathrm{~min}$ into RUN 1) due to an injury sustained elsewhere and was removed from the final sample. The characteristics of the nine remaining participants are summarised in Table 1. All participants acknowledged compliance with the pre-trial procedures and successfully replicated the same experimental protocol at both sessions. Baseline BW (Placebo $=70.5 \pm 5.4 \mathrm{~kg}, \mathrm{CBD}=70.7 \pm 5.5 \mathrm{~kg}$, $t(8)=0.984, p=0.354)$ and $\mathrm{U}_{\mathrm{SG}}($ Placebo $=1.015 \pm 0.008$, $\mathrm{CBD}=1.015 \pm 0.009, t(7)=0.025, p=0.980)$ as well as the laboratory temperature (Placebo $=21.5 \pm 0.44{ }^{\circ} \mathrm{C}$, $\mathrm{CBD}=21.2 \pm 0.3^{\circ} \mathrm{C}, t(8)=1.538, p=0.163$ ) and humidity $($ Placebo $=54.8 \pm 8.6 \%, C B D=56.7 \pm 7.4 \%, t(8)=0.634$, $p=0.544)$ were similar across sessions. Participants consumed $4444 \pm 390 \mathrm{~kJ}$ and $140 \pm 9 \mathrm{~g}$ CHO for dinner the night prior to each session. Participants consumed $1291 \pm 238 \mathrm{~kJ}, 50.2 \pm 8.6 \mathrm{~g} \mathrm{CHO}$ and $389 \pm 220 \mathrm{~mL}$ of water during breakfast on the day of each session. Water consumption Post-RUN 1 and 2 was $343 \pm 109 \mathrm{~mL}$ and $425 \pm 153 \mathrm{~mL}$, respectively.

Plasma Cannabinoid and Endocannabinoid Concentrations Plasma CBD, 7-COOH-CBD, 7-OH-CBD and 6-OHCBD concentrations are displayed in Figs. 3a, c. $C_{\max }$ and $T_{\max }$ were estimated as $174 \pm 100 \mathrm{ng} \cdot \mathrm{mL}^{-1}$ and $206 \pm 25$ min, respectively. Although sessions were separated by an average of $8.6 \pm 2.4$ days (and a minimum of 7 days), all five of the participants who completed the CBD session before the placebo session had detectable levels of 7-COOH-CBD in plasma at Baseline on their placebo session $\left(\leq 19.1 \mathrm{ng} \cdot \mathrm{mL}^{-1}\right)$; two also had very low concentrations of CBD $\left(\leq 0.8 \mathrm{ng} \cdot \mathrm{mL}^{-1}\right)$. THC, $11-\mathrm{OH}-$ THC and 11-COOH-THC were not detected in any samples.

Plasma AEA concentrations are displayed in Fig. 3b. AEA showed a significant effect of Time (AEA: $\left.F_{1,8}=37.46, p<0.001, \eta \mathrm{p}^{2}=0.83\right)$ with post hoc comparisons revealing lower plasma AEA concentrations PreRUN 1 compared to Baseline $(p<0.001)$ and higher AEA concentrations Post-RUN 1, Post-RUN 2 and 1 h PostRUN 2, compared to Baseline and Pre-RUN $1(p$ 's $<0.05)$. Plasma AEA concentrations appeared possibly reduced Post-RUN 2 under the CBD treatment, relative to placebo (Cohen's $d_{\mathrm{z}}=-1.492$, 85\% CI's $=-2.190,-0.794$ ). The effect of CBD at all other timepoints was uncertain.

\section{Submaximal Exercise ("RUN 1")}

The outcomes measured during RUN 1 are displayed in Figs. 4 and 5; Cohen's $d_{z}$ effect sizes are presented in Fig. 7 . The effects of CBD on HR, blood glucose, RPE, RER, RR, $V_{\mathrm{E}}, V_{\mathrm{T}}$ and estimated fluid loss were uncertain. Blood lactate at $40_{\mathrm{EX}}($ Placebo $=3.73 \pm 1.91, \mathrm{CBD}=7.03 \pm 6.68)$, $\mathrm{VO}_{2}$ at $37_{\mathrm{EX}} \quad\left(\right.$ Placebo $=2647 \pm 268 \quad \mathrm{~mL} \cdot \mathrm{min}^{-1}$, $\left.\mathrm{CBD}=2685 \pm 251 \mathrm{~mL} \cdot \mathrm{min}^{-1}\right), \quad \mathrm{VCO}_{2}$ at $24_{\mathrm{EX}} \quad(\mathrm{Pla}-$ cebo $=2596 \pm 275 \mathrm{~mL} \cdot \mathrm{min}^{-1}, \mathrm{CBD}=2671 \pm 263 \mathrm{~mL} \cdot \mathrm{min}^{-1}$ ) and $\quad 37_{\mathrm{EX}} \quad\left(\right.$ Placebo $=2599 \pm 281 \quad \mathrm{~mL} \cdot \mathrm{min}^{-1}$, $\left.\mathrm{CBD}=2710 \pm 304 \mathrm{~mL} \cdot \mathrm{min}^{-1}\right)$ and ratings of pleasure on the Feelings Scale at $20_{\mathrm{EX}}($ Placebo $=2.4 \pm 1.3, \mathrm{CBD}=3.1 \pm 1.3)$ and $40_{\mathrm{EX}}($ Placebo $=1.7 \pm 1.6, \mathrm{CBD}=2.4 \pm 1.2)$ all appeared possibly elevated with the $\mathrm{CBD}$ treatment, relative to placebo Effects were uncertain at all other timepoints.

\section{Incremental Exercise ("RUN 2")}

The outcomes measured during RUN 2 are displayed in Fig. 6; Cohen's $d_{\mathrm{z}}$ effect sizes are presented in Fig. 7. The effects of CBD on $\mathrm{HR}_{\max }$, TTE, blood lactate, blood glucose, RR and $V_{\mathrm{E}}$ were uncertain. $\mathrm{VO}_{2 \max }$ (Placebo $=3868 \pm 577 \mathrm{~mL} \cdot \mathrm{min}^{-1}, \mathrm{CBD}=3987 \pm 462 \mathrm{~mL} \cdot \mathrm{min}^{-1}$ ), $\mathrm{VCO}_{2 \max }, \quad\left(\right.$ Placebo $=4594 \pm 704 \quad \mathrm{~mL} \cdot \mathrm{min}^{-1}$, 


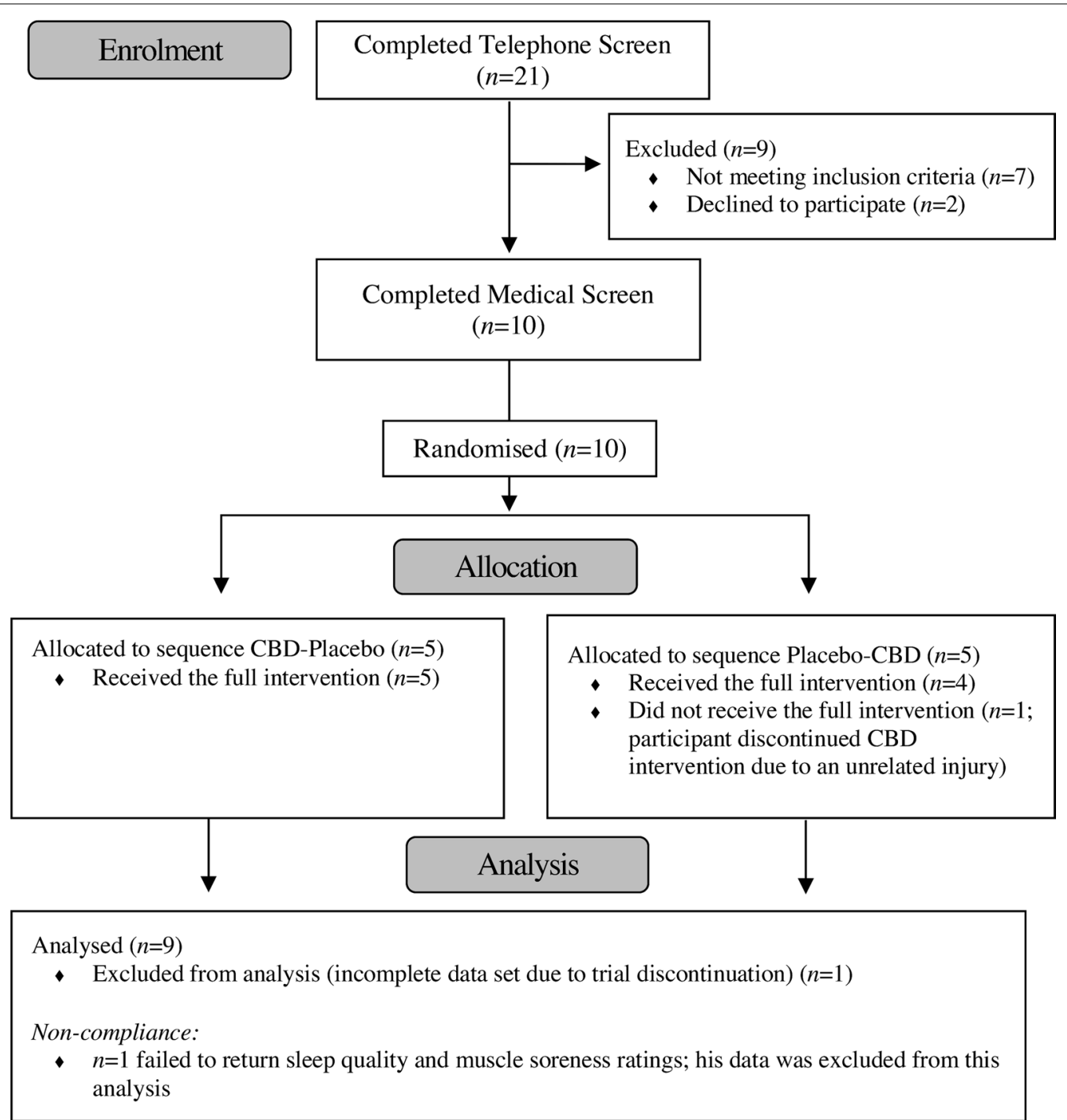

Fig. 2 Consolidated Standards of Reporting Trials (CONSORT) diagram. Recruitment was completed when the target sample size of $n=10$ participants had been randomised

$\left.\mathrm{CBD}=4871 \pm 524 \mathrm{~mL} \cdot \mathrm{min}^{-1}\right), \mathrm{RER}_{\max }($ Placebo $=1.19 \pm 0.07$, $\mathrm{CBD}=1.23 \pm 0.07)$ and $V_{\mathrm{t}} \quad($ Placebo $=2862 \pm 680 \mathrm{~mL}$, $\mathrm{CBD}=2957 \pm 608 \mathrm{~mL}$ ) all appeared possibly elevated with the CBD treatment, relative to placebo. Neither TTE (Placebo $=1246 \pm 197 \mathrm{~s}, \quad \mathrm{CBD}=1286 \pm 150 \mathrm{~s}, \quad t(8)=0.528$, $p=0.612)$ nor $\mathrm{VO}_{2 \max } \quad\left(\right.$ Placebo $=3868 \pm 577 \mathrm{~mL} \cdot \mathrm{min}^{-1}$, $\left.\mathrm{CBD}=3987 \pm 462 \mathrm{~mL} \cdot \mathrm{min}^{-1}, t(8)=0.067, p=0.948\right) \mathrm{dem}-$ onstrated significant trial order effects.

\section{Serum Biomarkers}

Serum TNF- $\alpha$, IL- $1 \beta$, IL-6, Mb, CK, LPS and Claudin-3 concentrations are displayed in Additional file 1.

TNF- $\alpha$, IL-6, Mb, CK and LPS showed significant effects of Time (TNF- $\alpha$ : $F_{1,8}=3.19, p=0.045, \eta \mathrm{p}^{2}=0.31$;
IL-6: $F_{1,8}=15.06, p<0.001, \eta \mathrm{p}^{2}=0.65 ; \mathrm{Mb}: F_{1,8}=10.36$, $p<0.001, \quad \eta \mathrm{p}^{2}=0.56 ; \quad \mathrm{CK}: \quad F_{1,8}=21.00, \quad p=0.001$, $\eta \mathrm{p}^{2}=0.72$; LPS: $\left.F_{1,8}=4.34, p=0.046, \eta \mathrm{p}^{2}=0.35\right)$. Post hoc comparisons revealed higher serum IL-6 and Mb concentrations Post-RUN 1, Post-RUN 2 and 1 h PostRUN 2 compared to Baseline ( $p$ 's $<0.05)$. LPS concentrations were also higher Post-RUN $2(p=0.021)$ and $1 \mathrm{~h}$ Post-RUN $2(p=0.020)$ compared to Baseline. TNF- $\alpha$ concentrations were higher Post-RUN $2(p=0.016)$ and 1 h Post-RUN $2(p=0.026)$ than Post-RUN 1.

Cohen's $d_{z}$ effect sizes were calculated for those biomarkers wherein an exercise-induced change was observed ("Statistical analysis" section). These results are presented in Fig. 8. The effects of CBD on TNF- $\alpha$, IL-6, 
Table 1 Participant characteristics $(n=9)$

\begin{tabular}{ll}
\hline Age $(\mathrm{y})$ & $33(8)(24-43)$ \\
Weight $(\mathrm{kg})$ & $71.2 \pm 5.3(63.1-78.0)$ \\
Height $(\mathrm{cm})$ & $181 \pm 7(168-190)$ \\
$\mathrm{VO}_{2 \mathrm{max}}\left(\mathrm{mL} \cdot \mathrm{kg}^{-1} \cdot \mathrm{min}^{-1}\right)$ & $57.4 \pm 4.0(53.1-65.0)$ \\
Running distance $\left(\mathrm{km} \cdot \mathrm{wk}^{-1}\right)$ & $63 \pm 21(40-100)$ \\
Time since reported last cannabis use $(n)$ & \\
$\quad 3-12$ months & 0 \\
$1-2$ years & 2 \\
$2-4$ years & 3 \\
$>4$ years & 2 \\
$\quad$ No prior use & 2 \\
Lifetime cannabis exposure $(n)$ & \\
$\leq 10$ uses & 5 \\
$>10$ uses & 2 \\
No prior use & 2 \\
Lifetime CBD exposure $(n)$ & \\
$\leq 10$ uses & 0 \\
$>10$ uses & $1^{\text {a }}$ \\
No prior use & 8
\end{tabular}

$\mathrm{VO}_{2 \max }$ : Aerobic capacity. Values are mean $\pm \mathrm{SD}$ (range), median (IQR) (range) and number of participants $(n)$, as appropriate

a $1-2$ y since last use

CK and LPS were uncertain. With CBD treatment: IL-1 $\beta$ concentrations appeared possibly decreased Post-RUN 2 (Placebo $=0.09 \pm 0.06 \mathrm{pg} \cdot \mathrm{mL}, \mathrm{CBD}=0.05 \pm 0.04 \mathrm{pg} \cdot \mathrm{mL}$ ) and 1-h Post-RUN 2 (Placebo $=0.06 \pm 0.05 \mathrm{pg} \cdot \mathrm{mL}$, $\mathrm{CBD}=0.04 \pm 0.02 \mathrm{pg} \cdot \mathrm{mL}$ ), while $\mathrm{Mb}$ concentrations appeared possibly increased $1 \mathrm{~h}$ Post-RUN 2 with $\mathrm{CBD}$ relative to placebo (Placebo $=748 \pm 124 \mathrm{ng} \cdot \mathrm{mL}$, $\mathrm{CBD}=845 \pm 183 \mathrm{ng} \cdot \mathrm{mL}$ ). Effects were uncertain at all other timepoints.

\section{Gastrointestinal (GI) Comfort}

GI comfort VAS ratings are presented in Additional file 1. These outcomes were not subjected to further analysis as participants only ever reported low levels of GI discomfort $(<10 \mathrm{~mm})$ (except one individual, who rated all symptoms $>10 \mathrm{~mm}$ on both sessions).

\section{Subjective Feelings}

STAI-S and POMS scores are presented in Additional file 1. The STAI-S and the "Tension", "Depression", "Anger" and "Confusion" sub-scales of the POMS were not subjected to further analysis as participants only ever recorded low scores on these scales. Cohen's $d_{\mathrm{z}}$ effect sizes for the "Vigour", "Esteem" and "Fatigue" subscales are presented in Fig. 9. The effect of CBD on "Vigour"

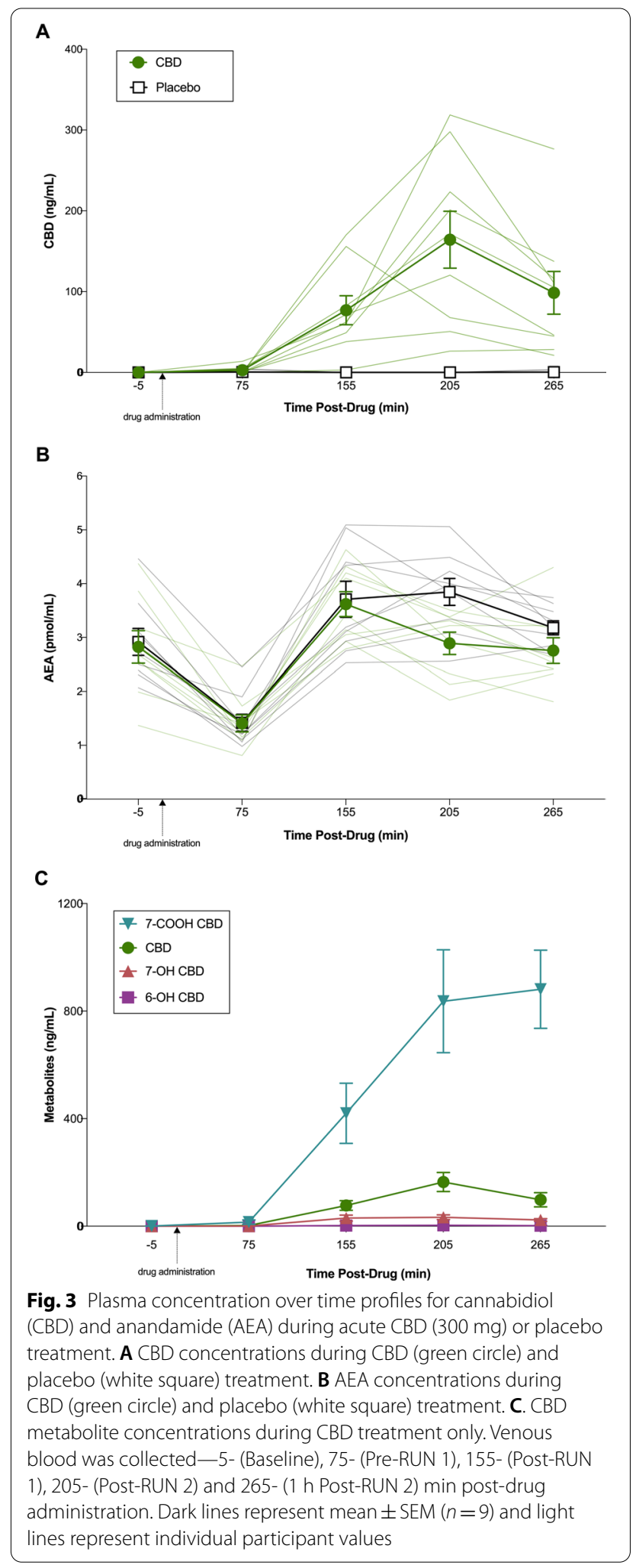




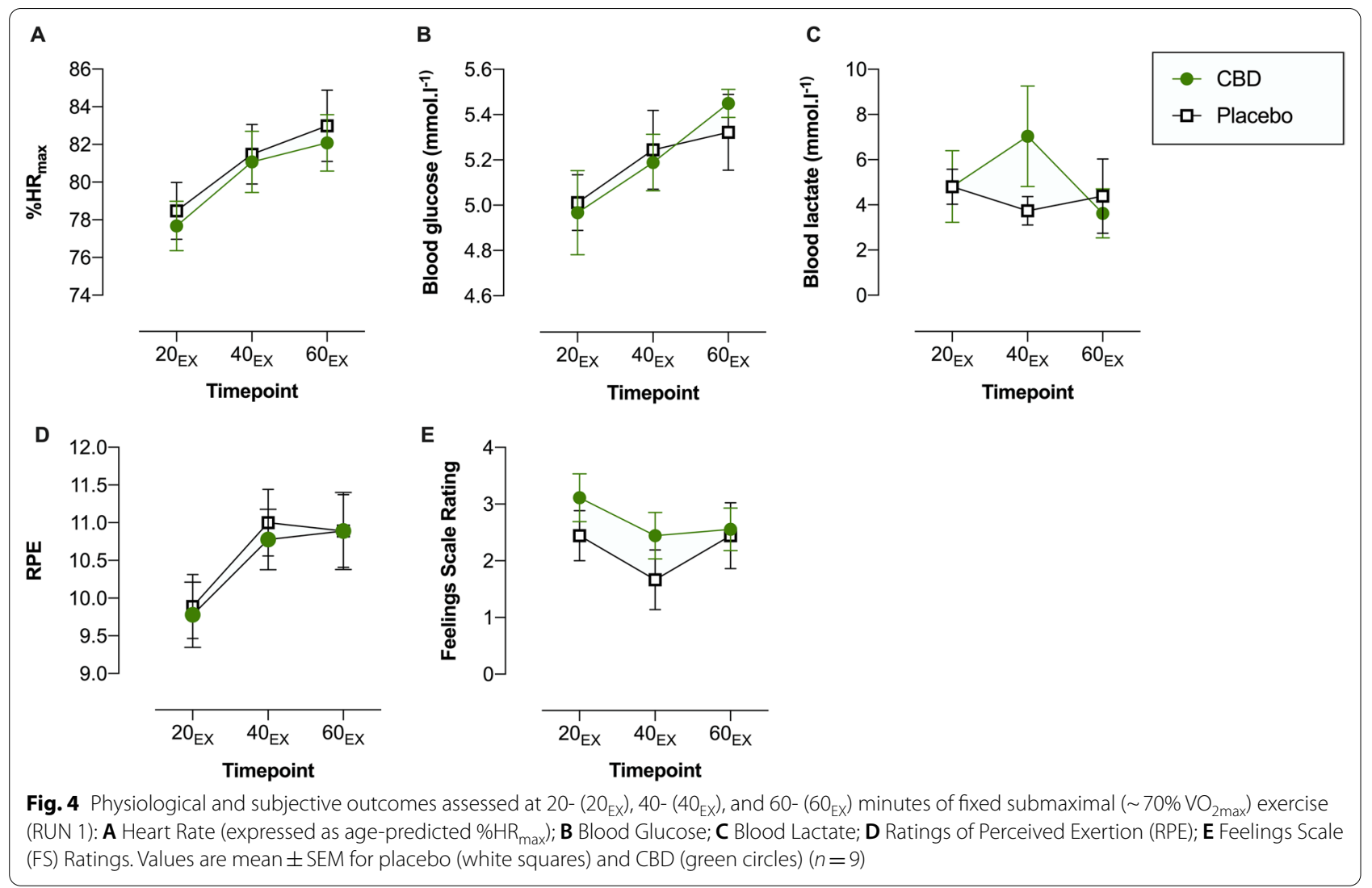

and "Esteem" was uncertain, while "Fatigue" appeared possibly reduced Post-RUN $1 \quad$ (Placebo $=2.0 \pm 1.9$, $\mathrm{CBD}=1.1 \pm 1.7)$ and possibly elevated $1 \mathrm{~h}$ PostRUN 2 with CBD treatment, relative to placebo (Placebo $=1.3 \pm 1.7, \mathrm{CBD}=2.1 \pm 2.1$ ). Effects were uncertain at all other timepoints.

\section{Resting Heart Rate (HR) and Blood Pressure (BP)}

Resting HR and BP measurements are presented in Additional file 1; Cohen's $\mathrm{d}_{\mathrm{z}}$ effect sizes are presented in Fig. 10. The effect of CBD on systolic and diastolic BP was uncertain. HR appeared possibly reduced with CBD treatment relative to placebo Pre-RUN 1 (Placebo $=55 \pm$ $4 \mathrm{bpm}, \mathrm{CBD}=51 \pm 6 \mathrm{bpm}$ ), although this difference also appeared to be present at Baseline. Effects were uncertain at all other timepoints.

\section{Sleep Quality and Next-Day Muscle Soreness}

The effect of CBD on next-day subjective muscle soreness (Placebo $=1.8 \pm 0.3, \mathrm{CBD}=1.6 \pm 0.3$; Cohen's $d_{\mathrm{z}}=-0.195$, $85 \%$ CI's: $-0.709,0.319$ ) and sleep quality (Placebo = $3.3 \pm 0.2, \mathrm{CBD}=3.4 \pm 0.7$; Cohen's $d_{\mathrm{z}}=0.195,85 \%$ CI's: $-0.319,0.709)$ was uncertain. (Nb. These analyses were performed at $n=8$ as one participant failed to return his ratings after one session).

\section{Participant Expectations and Blinding}

Prior to participation, most participants $(n=6)$ believed that CBD would have a "slightly positive" effect on their endurance exercise performance; one believed it would have a "slightly negative" effect, while the remainder $(n=2)$ were "unsure" of its potential effects.

Only one of the nine participants (11\%) correctly identified the session on which they received CBD; three (30\%) correctly identified the session on which they received the placebo. When participants were correct, they were only "somewhat" confident in their prediction. Participants were either incorrect $(n=6)$ or unsure $(n=8)$ which treatment they received during the remaining trials.

\section{Adverse Events}

No serious adverse events occurred during this trial. One participant fainted during the Baseline (pre-treatment) blood draw; this treatment session was terminated and rescheduled.

\section{Discussion}

This pilot study investigated the effects of acute, oral CBD treatment $(300 \mathrm{mg}$ ) versus placebo on physiological and psychological responses to aerobic exercise in a 


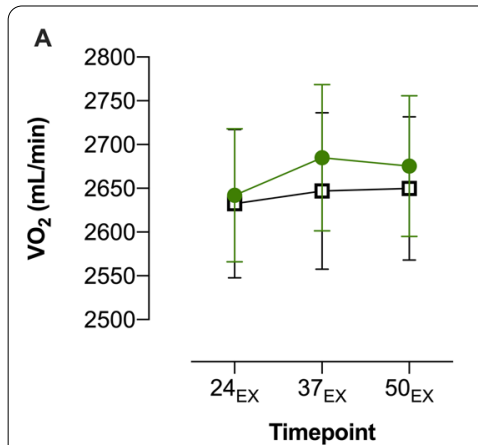

D

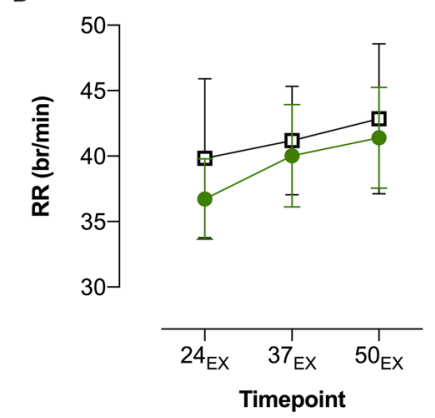

B

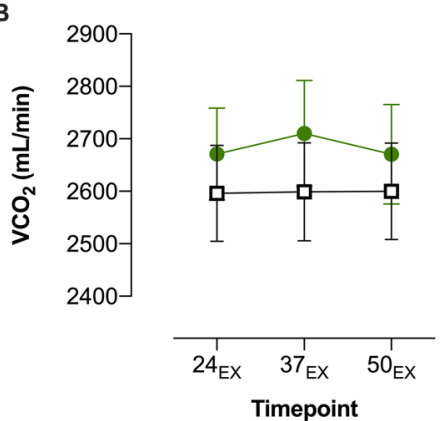

E

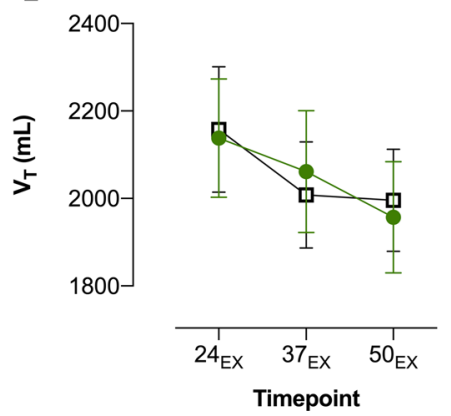

C

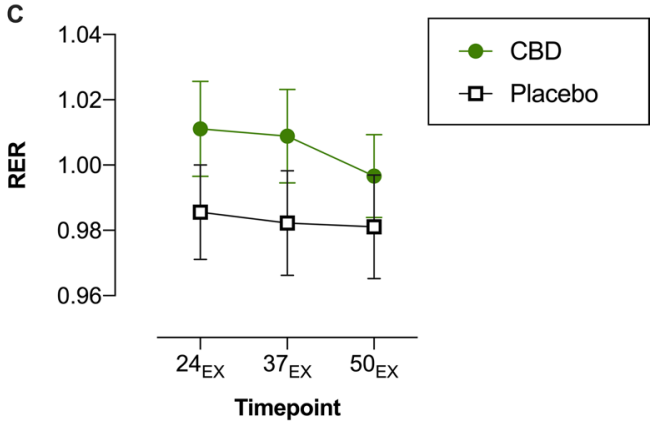

$\mathbf{F}$

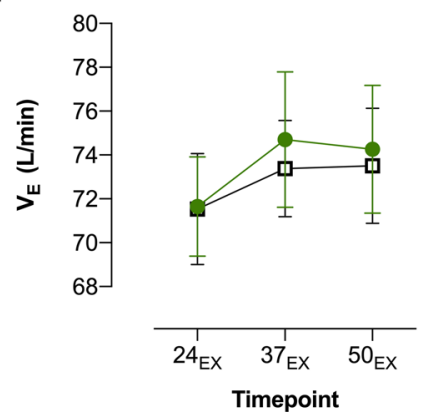

Fig. 5 Respiratory gas measures assessed during fixed submaximal $\left(\sim 70 \% \mathrm{VO}_{2 \mathrm{max}}\right)$ exercise (RUN 1). A Oxygen Consumption $\left(\mathrm{VO}_{2}\right)$; $\mathbf{B}$ Carbon Dioxide Production ( $\left.\mathrm{VCO}_{2}\right)$; C Respiratory Exchange Ratio (RER); $\mathbf{D}$ Respiratory Rate (RR); E Tidal Volume $\left(\mathrm{V}_{\mathrm{T}}\right)$ and $\mathbf{F}$ Minute Ventilation $\left(V_{\mathrm{E}}\right)$. Breath-by-breath registrations of respiratory gases were collected at three intervals (24-32 (24 EX), 37-45 (37 EX) and 50-58 (50 EX $)$ minutes) during RUN 1. These measures were averaged across each 8 -min collection period prior to analysis. Values are mean \pm SEM for placebo (white squares) and $\mathrm{CBD}$ (green circles) $(n=9)$

small sample of male endurance-trained runners. Effects were considered worthy of further investigation if the $85 \%$ CI around Cohen's $\mathrm{d}_{\mathrm{z}}$ included \pm 0.5 but not zero. Results suggest that CBD may alter several key parameters, including submaximal $\left(\mathrm{VO}_{2}\right)$ and maximal $\left(\mathrm{VO}_{2 \max }\right)$ oxygen consumption, feelings of pleasure during submaximal exercise and markers of exercise-induced inflammation. However, it is important to stress that the analytical approach employed is susceptible to Type I error (i.e. identifying "false" effects) and was selected to inform the design of future "definitive" trials [23]. These initial observations should, therefore, be interpreted with caution and not taken as compelling evidence of "effect".

CBD appeared to increase $\mathrm{VO}_{2}$ (and $\mathrm{VCO}_{2}$ ) during 60 min of submaximal exercise (RUN 1). An increase in $\mathrm{VO}_{2}$ (at a fixed workload) may suggest a reduction in running economy, and therefore, a detrimental effect of $\mathrm{CBD}$ on aerobic exercise performance. However, the difference was relatively subtle $\left(37_{\mathrm{EX}}:+38 \pm 48 \mathrm{~mL} \cdot \mathrm{min}^{-1}\right.$, $50_{\mathrm{EX}}:+26 \pm 55 \mathrm{~mL} \cdot \mathrm{min}^{-1}$ ) compared to that of other interventions known to influence $\mathrm{VO}_{2}$ (e.g. ketogenic diets: $+90-140 \mathrm{~mL} \cdot \mathrm{min}^{-1} \quad$ [40]; dietary nitrates: $\left.-143 \mathrm{~mL} \cdot \mathrm{min}^{-1}[41]\right)$, corresponding to only a $2.3 \%$ increase in estimated energy expenditure $(+82 \pm 121 \mathrm{~kJ}$; based on the equations of Frayn [42]). Furthermore, it was not accompanied by an increase in HR or RPE, nor a decrease in TTE as one might anticipate [40]. In fact, in addition to $\mathrm{VO}_{2}, \mathrm{CBD}$ appeared to increase $\mathrm{VO}_{2 \max }(+$ $\left.119 \pm 206 \mathrm{~mL} \cdot \mathrm{min}^{-1} ;+1.5 \pm 2.8 \mathrm{~mL} \cdot \mathrm{min}^{-1} \cdot \mathrm{kg}^{-1}\right)$. Thus, if present, any detrimental effect of CBD on running economy appears to be small and seems unlikely to impair aerobic exercise performance.

The potential mechanism by which CBD might have affected $\mathrm{VO}_{2}$ responses in the present study is difficult to predict given its multiple pharmacological actions [22] and the limited amount of research in this field. Nonetheless, some mechanisms can be excluded. First, the current findings (and some previous research [43]) suggest that alterations in breathing patterns (i.e. RR, $V_{\mathrm{T}}$, $V_{\mathrm{E}}$ ) are unlikely to explain the observed increase in $\mathrm{VO}_{2}$. Second, while participants could have modified their running biomechanics on the treadmill (e.g. stride frequency, strike pattern, ground contact time), changing muscle recruitment and therefore $\mathrm{VO}_{2}$, this would not be expected to increase $\mathrm{VO}_{2 \max }$. Third, while preferential utilisation of fat as a metabolic substrate can increase $\mathrm{VO}_{2}$ [40], CBD did not appear to decrease submaximal RER. Fourth, while impairments in mitochondrial 

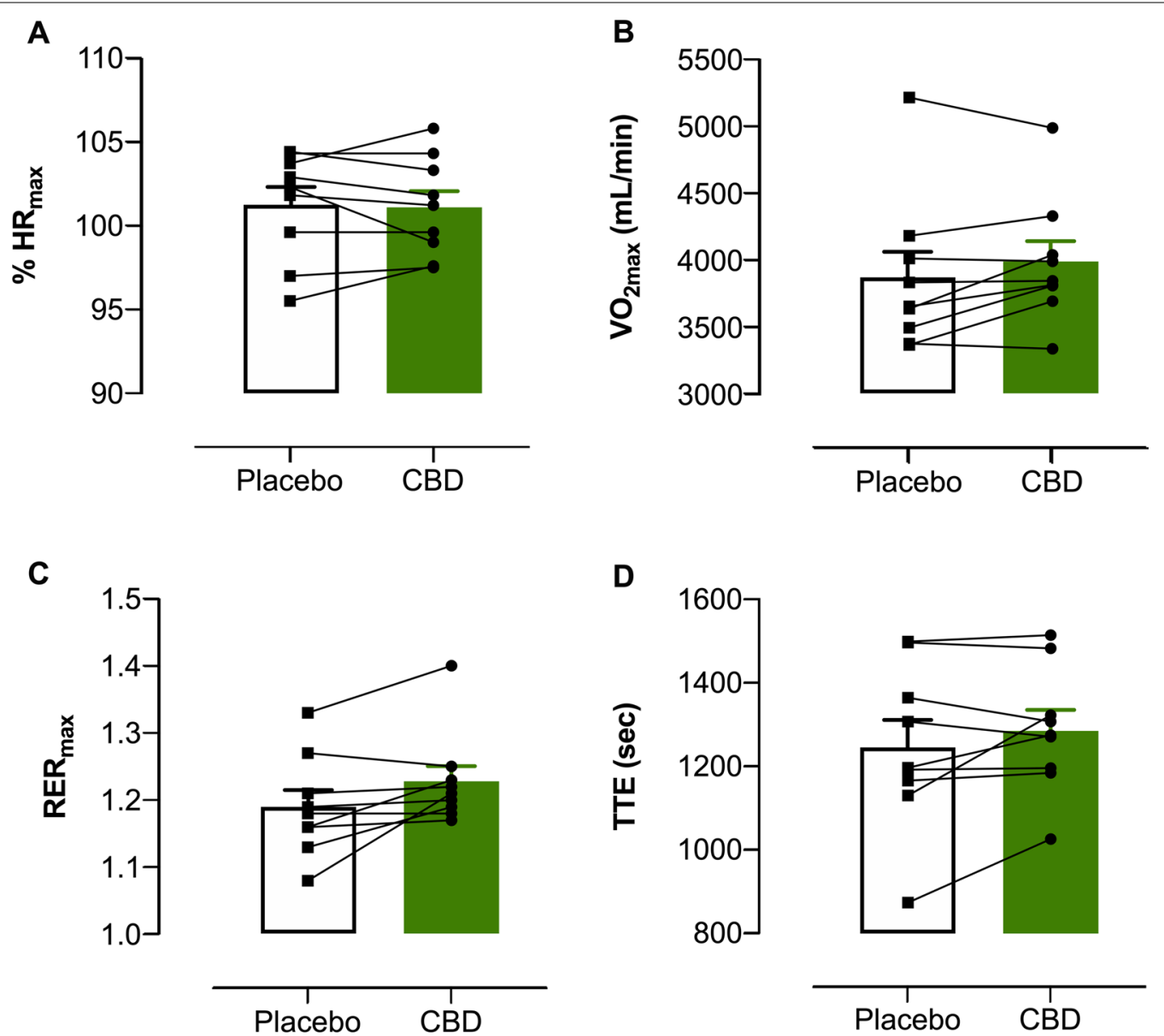

Fig. 6 Outcomes measured during the incremental exercise test to volitional exhaustion (RUN 2). A Maximum Heart Rate (expressed as \% HR max); $\mathbf{B}$ Maximum Oxygen Consumption $\left(\mathrm{VO}_{2 \text { max }}\right)$; $\mathbf{C}$ Respiratory Exchange Ratio (RER) and $\mathbf{D}$ Time to Exhaustion (TTE). Values are mean $\pm \mathrm{SEM}$ for placebo (white) and CBD (green); each line represents one individual participant $(n=9)$

function (e.g. increased non-energetic proton leak across the inner membrane) can increase $\mathrm{VO}_{2}$ [44], this would not be expected to increase $\mathrm{VO}_{2 \max }$ [45] (and would likely decrease TTE). Furthermore, most in vivo studies find that CBD improves aspects of mitochondrial function [46-49], although some in vitro (cellular) studies, usually involving high concentrations of CBD (e.g. $>5 \mu \mathrm{M}$ ), have reported detrimental effects [50-54].

One possible explanation for the observed increase in $\mathrm{VO}_{2}$ and $\mathrm{VO}_{2 \max }$ is that CBD increased tissue blood flow via vasodilation. Indeed, studies have shown that nitrateand ascorbic acid-induced vasodilation can increase skeletal muscle blood flow and $\mathrm{VO}_{2}$ during hand-grip exercise $[55,56]$. Findings from several preclinical studies also suggest that in vitro CBD treatment (i.e. $\leq 2-\mathrm{h}$ exposure to $1-10 \mu \mathrm{M})$ can induce vasodilation in isolated arteries of rats [57-59] and humans [60]. A small clinical trial $(n=9)$ further reported that CBD $(600 \mathrm{mg})$ reduced resting systolic $\mathrm{BP}(\sim 6 \mathrm{mmHg})$ and total peripheral resistance during hand-grip exercise in normotensive males [61]. This mechanism could also explain why the observed increase in $\mathrm{VO}_{2}$ was not accompanied by a clear increase in HR or RPE; nor decrease in TTE, as described above. That said, BP did not appear to be affected in the current trial.

In terms of psychological effects, CBD appeared to improve affect (i.e. ratings of pleasure) during the first 40 -min of submaximal exercise $\left(20_{\mathrm{Ex}}:+0.7 \pm 0.9\right.$; $\left.40_{\mathrm{EX}}:+0.8 \pm 1.1\right)$ but with no difference at $60_{\mathrm{EX}}$. It is important to note that the ratings obtained at $60_{\mathrm{EX}}$ may have been influenced by the expectation of completing the exercise bout [62]; that is, participants "felt better" at $60_{\mathrm{EX}}$ because they knew they were close to finishing the exercise task. Indeed, affect, which often decreases as exercise progresses [62], tended to increase from 40 to $60_{\mathrm{EX}}$ on both treatments (Placebo: $+0.8 \pm 1.5$; $\mathrm{CBD}:+0.1 \pm 0.3)$, particularly placebo. Thus, the results at $60_{\mathrm{EX}}$ should be interpreted with caution. The absence 
Cohen's $d z(85 \% \mathrm{Cl})$

\begin{tabular}{|c|c|c|}
\hline RUN 1 & $\begin{array}{l}\text { Heart Rate } \\
20 E X \\
40 E X \\
60 E X\end{array}$ & $\begin{array}{l}(-0.290[-0.780,0.200]) \\
(-0.153[-0.636,0.330]) \\
(-0.337[-0.830,0.157])\end{array}$ \\
\hline & $\begin{array}{l}\mathrm{VO}_{2}(\mathrm{ml} / \mathrm{min} \\
24 \mathrm{EX} \\
37 \mathrm{EX} \\
50 \mathrm{EX}\end{array}$ & $\begin{array}{r}(0.199[-0.286,0.683]) \\
(0.802[+0.250,1.354]) \\
(0.464[-0.041,0.969])\end{array}$ \\
\hline & $\begin{array}{l}\mathrm{VCO}_{2}(\mathrm{~m} l / \mathrm{m} \\
24 \mathrm{EX} \\
37 \mathrm{EX} \\
50 \mathrm{EX}\end{array}$ & $\begin{array}{r}(0.544[+0.030,1.058]) \\
(0.633[+0.107,1.159]) \\
(0.448[-0.056,0.951])\end{array}$ \\
\hline & $\begin{array}{l}\text { RER } \\
24 E X \\
37 E X \\
50 E X\end{array}$ & $\begin{array}{l}(0.443[-0.060,0.946]) \\
(0.410[-0.090,0.910]) \\
(0.299[-0.191,0.790])\end{array}$ \\
\hline & $\begin{array}{l}\text { RR (breath/ } \\
24 E X \\
37 E X \\
50 E X\end{array}$ & $\begin{array}{l}\text { in) } \\
\begin{array}{l}(-0.272[-0.761,0.217]) \\
(-0.342[-0.836,0.152]] \\
(-0.200[-0.684,0.285])\end{array}\end{array}$ \\
\hline & $\begin{array}{l}v_{t} \\
24 E X \\
37 E X \\
50 E X\end{array}$ & $\begin{array}{c}(-0.076[-0.557,0.404]) \\
(-0.299[-0.192,0.7909)) \\
(-0.400[-0.898,0.099])\end{array}$ \\
\hline & $\begin{array}{l}v_{E} \\
24 E X \\
37 E X \\
50 E X\end{array}$ & $\begin{array}{l}(0.031[-0.449,0.511]) \\
(0.259[-0.229,0.747]) \\
(0.150[-0.333,0.632])\end{array}$ \\
\hline & $\begin{array}{l}\text { BG } \\
20 E X \\
40 E X \\
60 E X\end{array}$ & $\begin{array}{l}(-0.127[-0.609,0.355]) \\
(-0.105[-0.586,0.376]) \\
(-0.250[-0.737,0.238])\end{array}$ \\
\hline & $\begin{array}{l}\text { BL } \\
20 E X \\
40 E X \\
60 E X\end{array}$ & $\begin{array}{c}(0.003[-0.477,0.483]) \\
(0.515[+0.004,1.026]) \\
(-0.127[-0.609,0.355])\end{array}$ \\
\hline & $\begin{array}{l}\text { RPE } \\
20 E X \\
40 E X \\
60 E X\end{array}$ & $\begin{array}{r}(-0.142[-0.625,0.340]) \\
(-0.229[-0.715,0.258]) \\
(0.000[-0.480,0.480])\end{array}$ \\
\hline & Feelings Sc & \\
\hline & $\begin{array}{l}20 \mathrm{EX} \\
40 \mathrm{EX} \\
60 \mathrm{EX}\end{array}$ & $\begin{array}{c}(0.770[+0.223,1.316]) \\
(0.712[+0.174,1.249]) \\
(0.095[-0.386,0.576])\end{array}$ \\
\hline & Fluid Loss & $(-0.054[-0.535,0.426])$ \\
\hline RUN 2 & $\mathrm{HR}_{\max }$ & $(-0.081[-0.562,0.400])$ \\
\hline & $\mathrm{VO}_{2 \max }$ & $(0.578[+0.059,1.096])$ \\
\hline & $\mathrm{vCO}_{2 \max }$ & $(0.950[+0.372,1.528])$ \\
\hline & RER $_{\max }$ & $(0.793[+0.243,1.343])$ \\
\hline & RR & $(-0.062[-0.542,0.419])$ \\
\hline & $v_{t}$ & $(0.543[+0.029,1.057])$ \\
\hline & $v_{E}$ & $(0.297[-0.193,0.788])$ \\
\hline & BG & $(-0.367[-0.863,0.129])$ \\
\hline & BL & $(0.118[-0.363,0.600])$ \\
\hline & TTE & $(0.461[-0.044,0.966])$ \\
\hline & Fluid Loss & $(-0.207[-0.692,0.278])$ \\
\hline
\end{tabular}

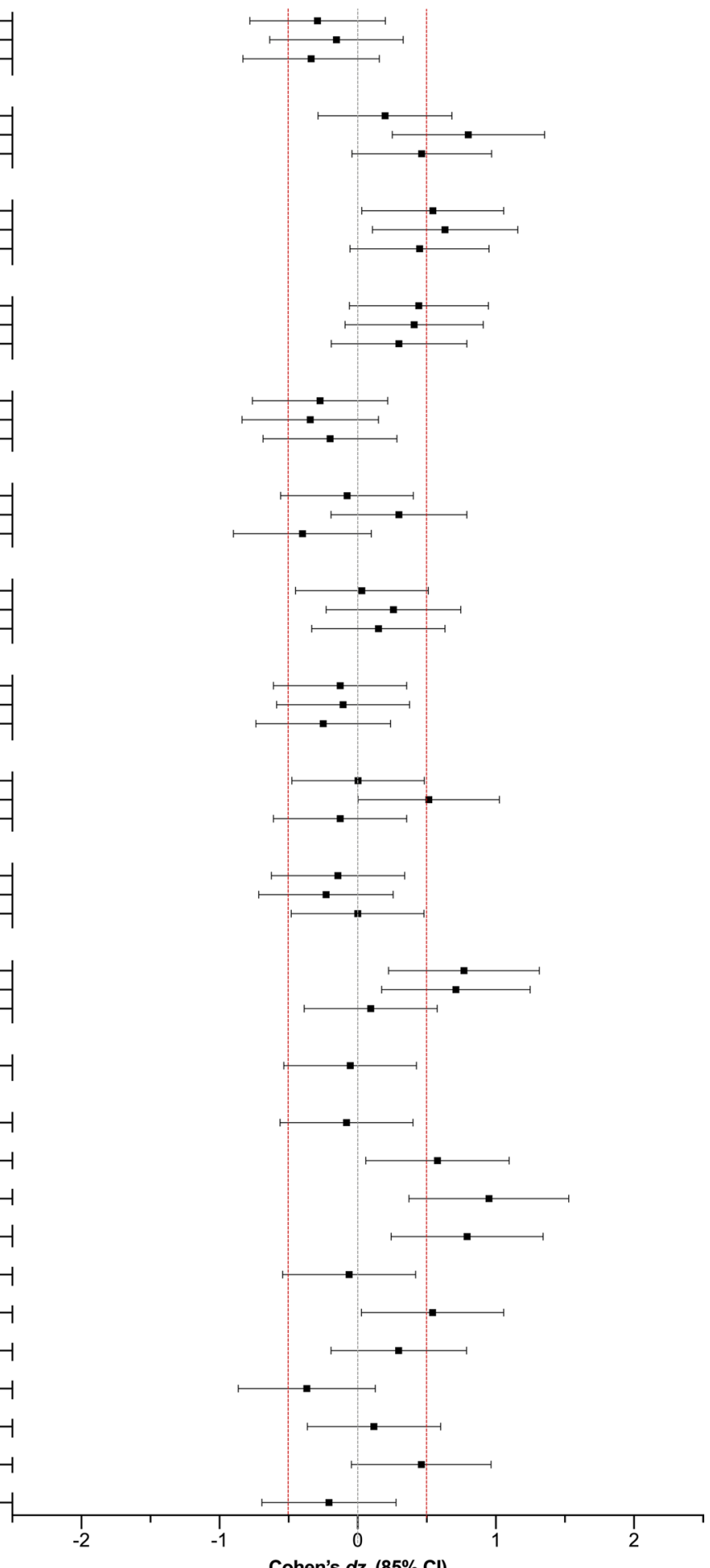

Fig. 7 Key physiological and psychological outcomes assessed during the submaximal (RUN 1) and exhaustive (RUN 2) exercise tasks. Values are Cohen's $d_{z}$ effect sizes and 85\% confidence intervals (Cl). BG: Blood Glucose; BL: Blood Lactate; EX: Minutes of Exercise; RER max: Maximum Respiratory Exchange Ratio; RPE: Ratings of Perceived Exertion; RR: Respiratory Rate; TTE: Time to Exhaustion; $\mathrm{V}_{\mathrm{E}}$ : Minute Ventilation; $\mathrm{V}_{\mathrm{t}}$ : Tidal Volume; $\mathrm{VCO}_{2}$ : Carbon Dioxide Expiration $\mathrm{VO}_{2}$ : Oxygen Consumption; $\mathrm{VCO}_{2 \text { max }}$ : Maximal $\mathrm{VCO}_{2} ; \mathrm{VO}_{2 \text { max }}$ : Maximal $\mathrm{VO}_{2}$. Positive effect sizes indicate an increase for $\mathrm{CBD}$ relative to placebo and negative effect sizes, a decrease. Confidence intervals were calculated using standard methods $(n=9)$ 


\section{Cohen's d $(85 \% \mathrm{Cl})$}

TNF- $\alpha$

Baseline

(0.110 [0.700, -0.479])

Post-RUN 1

$(-0.178[0.335,-0.691])$

Post-RUN 2

$(-0.312[0.209,-0.833])$

1h Post-RUN $2 \quad(-0.059[0.450,-0.569])$

IL-1 $\beta$

$\begin{array}{lcc}\text { Baseline } & (0.089[0.570,-0.392]) & - \\ \text { Post-RUN 1 } & (0.103[0.584,-0.378]) & - \\ \text { Post-RUN 2 } & (-0.930[-0.355,-1.504]) & - \\ \text { 1h Post-RUN 2 } & (-0.845[-0.286,-1.404]) & -\end{array}$

IL-6
Baseline
$(-0.228[0.259,-0.714])$
Post-RUN 1
$(0.224[0.710,-0.262])$
Post-RUN 2
$(-0.027[0.453,-0.507])$
1h Post-RUN $2 \quad(-0.090[0.391,-0.571])$

\section{Myoglobin}

$\begin{array}{lc}\text { Baseline } & (0.170[0.654,-0.313) \\ \text { Post-RUN 1 } & (0.233[0.719,-0.254]) \\ \text { Post-RUN 2 } & (0.330[0.823,-0.163]) \\ \text { 1h Post-RUN 2 } & (0.531[1.044,+0.018])\end{array}$

\section{Creatine Kinase}

Baseline $(-0.222[-0.264,-0.708])$

Post-RUN 1

$(-0.134[0.348,-0.616])$

Post-RUN 2

(0.337 [0.830, -0.157])

1h Post-RUN 2

$(0.179[0.663,-0.305])$

LPS

Baseline

$(0.119[0.600,-0.363])$

Post-RUN 1

(0.082 [0.563, -0.399])

Post-RUN 2

$(0.111[0.593,-0.370])$

1h Post-RUN $2 \quad(-0.058[0.423,-0.538])$

$$
-1
$$

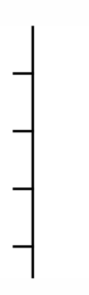

$$
\begin{aligned}
& -1 \\
& -1 \\
& -1 \\
& -1 \\
& -1 \\
& -1 \\
& -1
\end{aligned}
$$$$
-1
$$
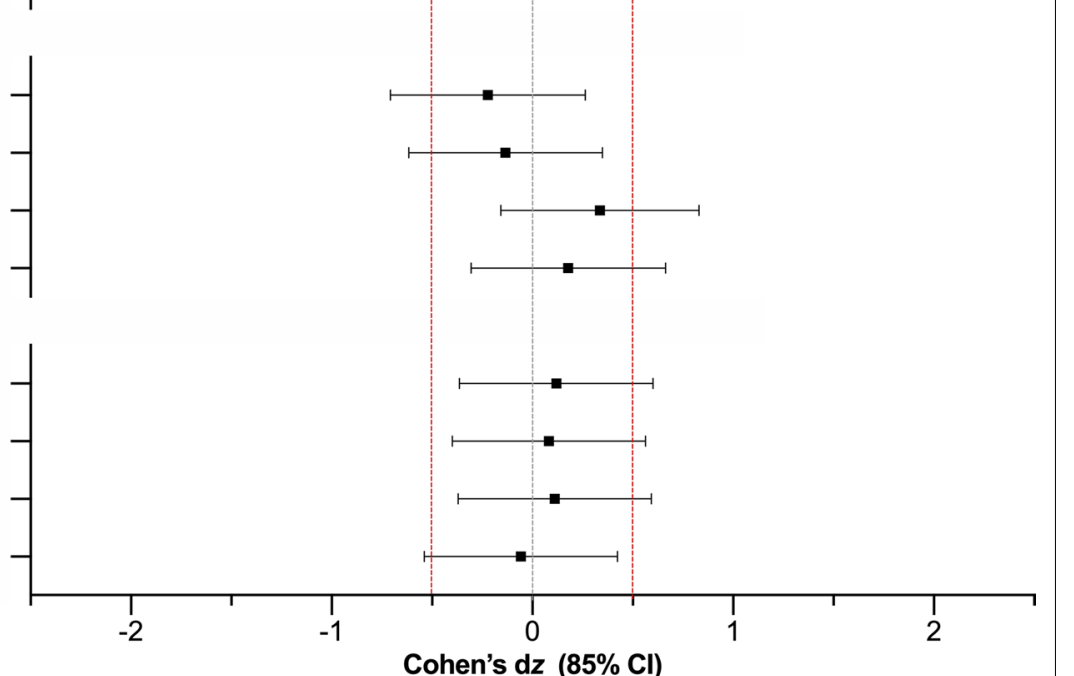

\section{Cohen's dz $(85 \% \mathrm{Cl})$}

Fig. 8 Biomarkers of exercise-induced inflammation assessed at Baseline, Post-RUN 1, Post-RUN 2 and 1 h Post-RUN 2. Values are Cohen's $d_{z}$ effect sizes and 85\% confidence intervals (CI) TNF-a: tumour necrosis factor-a; IL-1 $\beta$ : interleukin-1 $\beta$; IL-6: interleukin-6; LPS: liposaccharide binding protein. Positive effect sizes indicate an increase for CBD relative to placebo and negative effect sizes, a decrease. Confidence intervals were calculated using standard methods $(n=9)$ 


\section{Cohen's dz (85\% Cl)}

POMS Subscales

Vigour Baseline $\quad(0.040[0.520,-0.441])$

Pre-RUN $1 \quad(0.077[0.558,-0.404])$

Post-RUN $1 \quad(0.256[0.744,-0.232])$

Post-RUN $2 \quad(0.042[0.523,-0.438])$

1h Post-RUN $2 \quad(0.000[0.480,-0.480])$

Fatigue Baseline $\quad(0.162[0.645,-0.321])$

Pre-RUN $1 \quad(0.368[0.864,-0.128])$

Post-RUN $1 \quad(-0.612[-0.089,-1.135])$

Post-RUN $2 \quad(-0.066[0.415,-0.546])$

1h Post-RUN $2 \quad(0.712[1.249,+0.174])$

Esteem Baseline $\quad(0.216[0.702,-0.269])$

Pre-RUN $1 \quad(-0.145[0.337,-0.628])$

Post-RUN $1 \quad(-0.103[0.378,-0.584])$

Post-RUN $2 \quad(-0.030[0.450,-0.511])$

1h Post-RUN $2 \quad(-0.142[0.340,-0.625])$

POMS Total Mood Disturbance

$\begin{array}{ll}\text { Baseline } & (0.123[0.605,-0.359]) \\ \text { Pre-RUN 1 } & (0.092[0.573,-0.389]) \\ \text { Post-RUN 1 } & (-0.386[0.111,-0.884]) \\ \text { Post-RUN 2 } & (0.000[0.480,-0.480]) \\ \text { 1h Post-RUN 2 } & (0.227[0.714,-0.259])\end{array}$
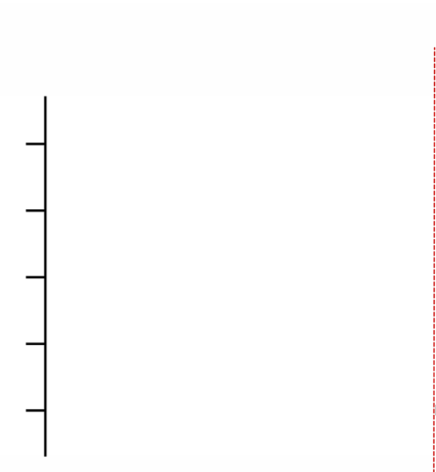


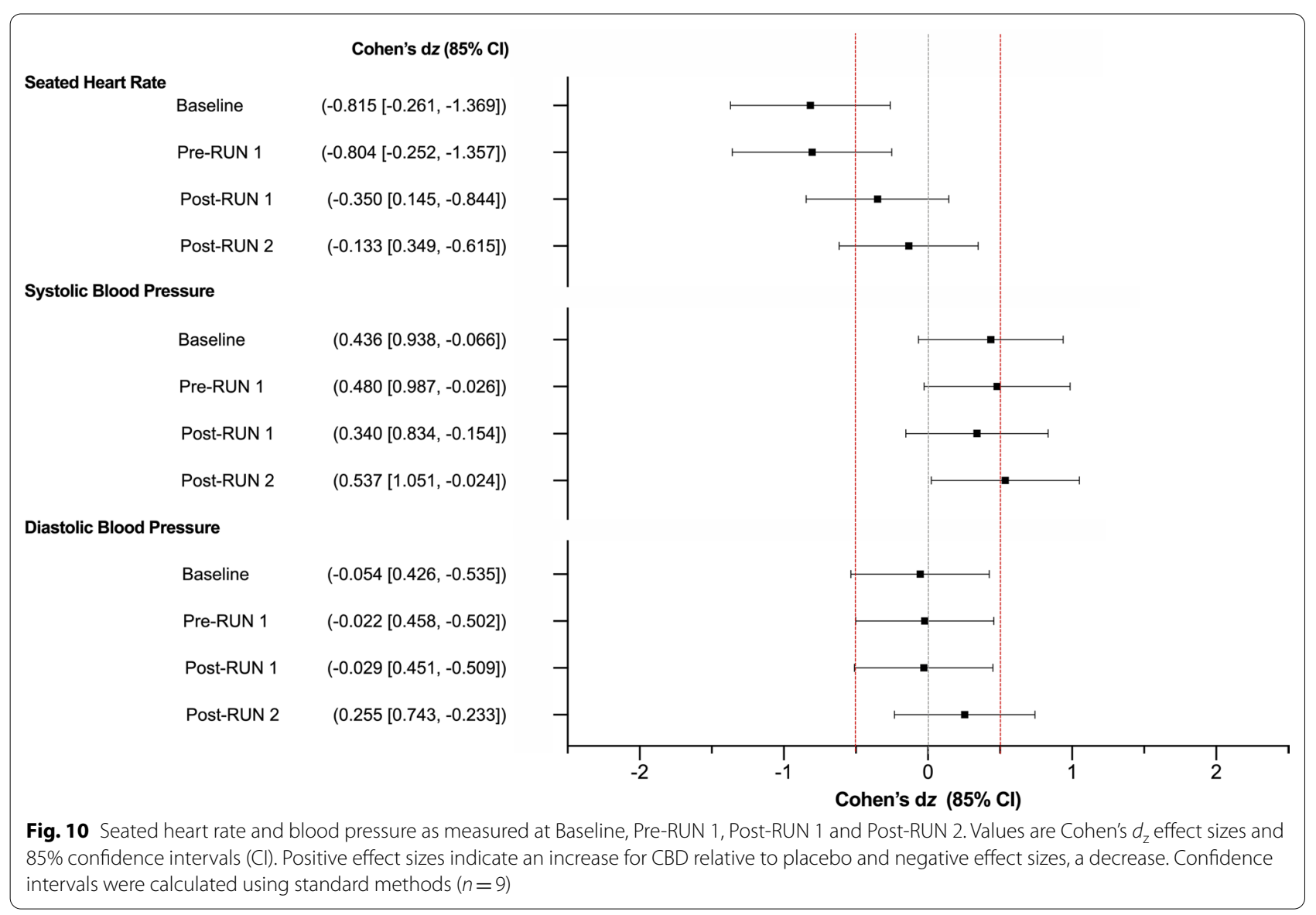

of any anxiolytic or other mood-altering effect of CBD should also be interpreted with caution as all participants recorded very low absolute scores on the STAI-S and POMS.

The mechanism via which CBD may improve affect during exercise is also difficult to predict. CBD has been shown to interact with a complex network of receptors and signalling pathways involved in mood regulation (e.g. $5-\mathrm{HT}_{1 \mathrm{~A}}, \mathrm{TRPV}_{1}$, PPARy, the cannabinoid type 1 receptor [CB1] [22]). An alternative possibility is that CBD, which has demonstrated some analgesic potential in humans [63], might have attenuated subjective feelings of pain, thereby increasing feelings of pleasure during exercise in the present study.

Exercise increased the serum concentrations of various biomarkers of systemic inflammation (i.e. TNF- $\alpha$, IL-1 $\beta$, IL-6), muscle damage (i.e. $\mathrm{Mb}, \mathrm{CK}$ ) and gastrointestinal damage (i.e. LPS) in the current trial. CBD appeared to suppress the exercise-induced increase in pro-inflammatory cytokine, IL-1 $\beta$, Post-RUN 2 and 1-h Post-RUN 2. This is consistent with the robust anti-inflammatory effects of CBD in animal models [64]. However, it should be noted that (even post-exercise) serum IL-1 $\beta$ concentrations were very low (often needing to be extrapolated from the standard curve); effects should therefore be interpreted with caution. In addition, neither IL-6 nor TNF- $\alpha$ concentrations appeared to be impacted by CBD. Regarding muscle damage, CBD appeared to increase $\mathrm{Mb}$ concentrations 1-h Post-RUN-2, suggesting an exacerbation of muscle damage. This unexpected change could have been driven by a small increase in TTE $(+39 \pm 85 \mathrm{~s})$ observed on the CBD treatment. While there is preliminary evidence suggesting that $\mathrm{CBD}$ may protect against some forms of GI damage [65], it did not appear to influence LPS concentrations in the current trial. Further research, employing more demanding exercise protocols (e.g. heat stress, eccentrically loaded exercise), may be required to better understand the anti-inflammatory and protective effects of CBD.

Several aspects of the current trial appeared to influence plasma AEA concentrations. First, all nine participants' plasma AEA concentrations: (1) decreased from Baseline to Pre-RUN 1; and (2) increased from Pre-RUN 1 to Post-RUN 1, regardless of the treatment administered. These effects are likely to be due to breakfast consumption and the completion of submaximal exercise 
(RUN 1), respectively. Indeed, previous studies report that circulating AEA concentrations decrease post-prandially [66] and increase following submaximal exercise (e.g. 70-85\% $\mathrm{HR}_{\max }$ ) $[67,68]$ with the endocannabinoid system (in general) believed to contribute to the regulation of energy intake and storage [69]. Second, CBD appeared to decrease plasma AEA concentrations PostRUN 2 relative to placebo. The only other study to have investigated the effect of CBD on circulating endocannabinoids, in fact, observed the opposite effect; that is, chronic CBD treatment (800 mg. $\mathrm{d}^{-1}$; 4 weeks) increased (resting) serum AEA concentrations in patients with schizophrenia [8]. Of course, the participant population, dosing regimen and experimental paradigm differed greatly between studies. While it is difficult to predict the mechanism by which CBD might have influenced AEA (and we cannot "rule out" an effect of the small increase in TTE observed on the CBD treatment), these findings add to a small body of evidence suggesting that CBD may modulate endocannabinoid tone.

This investigation does contain several limitations. First, as indicated above, the pilot trial was not formally powered to assess "effect". It also generated a number of uncertain results; however, it is important to recognise that some degree of "uncertainty" is also often present in $p$-values $>0.05$. Second, only male participants were recruited in this initial pilot study. As various physiological processes are influenced by the menstrual cycle, including substrate metabolism [70], this decision was made to minimise normal session-to-session variability and therefore maximise our capacity to detect effect (if present), given the limited sample size. Future studies should investigate the impact of CBD on both male and female physiology. Third, some participants had detectable albeit low levels of CBD $\left(n=2 ;<0.8 \mathrm{ng} \cdot \mathrm{mL}^{-1}\right)$ and(or) $7-\mathrm{COOH}-\mathrm{CBD}\left(n=5 ;<19.1 \mathrm{ng} \cdot \mathrm{mL}^{-1}\right)$ in plasma on their placebo trial after receiving the active treatment $\geq 7$-days prior. Although these low concentrations are unlikely to have had a meaningful effect on our results, future studies should consider extending the washout period between sessions (bearing in mind that this may require further standardisation of training and exercise behaviour). Fourth, plasma CBD concentrations remained relatively low during the initial stages of submaximal exercise (RUN 1); future studies, using similar formulations, may therefore benefit from delaying the start of exercise to better capture the observed $T_{\max }$. Fifth, the CBD dose used in this investigation $(300 \mathrm{mg}$ ) was relatively high (for a healthy population) and was selected to gain initial insights into CBD's effects. Future investigations may consider using doses that more closely resemble products available to (and used by) the general and athlete population.

\section{Conclusion}

These preliminary results suggest that acute, oral CBD treatment has the potential to alter key physiological and psychological responses during aerobic exercise. Indeed, its effects on $\mathrm{VO}_{2}$ responses, feelings of pleasure during exercise and exercise-induced inflammation appear worthy of further investigation. The absence of a clear detrimental effect on RPE, TTE and $\mathrm{VO}_{2 \max }$ also suggests that $\mathrm{CBD}$ is unlikely to impair aerobic exercise performance in endurance-trained males and may therefore have utility within the sporting context. Further research, involving a larger participant sample and different dosing regimens (e.g. chronic treatment, lower doses), is required to confirm and better understand these initial observations.

\section{Abbreviations}

BG: Blood glucose; BL: Blood lactate; BP: Blood pressure; BW: Body weight; CBD: Cannabidiol; CHO: Carbohydrate; Cl: Confidence interval; CK: Creatine kinase; EX: Minutes of exercise; GI: Gastrointestinal; HR: Heart rate; $\mathrm{HR}_{\max }$ : Maximal heart rate; IL-1 $\beta$ : Interleukin-1 $\beta$; IL-6: Interleukin-6; LPS: Liposaccharide; Mb: Myoglobin; MCT: Medium chain triglyceride; POMS: Profile of mood states; RER: Respiratory exchange ratio; RER $\mathrm{R}_{\text {max }}$ : Maximal respiratory exchange ratio; RR: Respiratory rate; SD: Standard deviation; SE: Standard error; STAI-S: Short Form State-Trait Anxiety Inventory; THC: Tetrahydrocannabinol; TNF-a: Tumour necrosis factor-a; TTE: Time to exhaustion; $\cup_{S G}$ Urine-specific gravity; $\mathrm{VCO}_{2}$ : Volume of carbon dioxide; $\mathrm{V} \mathrm{CO}_{2 \text { max }}$ : Maximal volume of carbon dioxide; $V_{\mathrm{E}}$ : Minute ventilation; $\mathrm{VO}_{2}:$ Volume of oxygen; $\mathrm{VO}_{2 \text { max }}$ : Maximal volume of oxygen; $V_{t}:$ Tidal volume

\section{Supplementary Information}

The online version contains supplementary material available at https://doi. org/10.1186/s40798-022-00417-y.

Additional file 1. Methods and results.

\section{Acknowledgements}

The authors would like to sincerely thank all participants for their contribution to the study. We would also like to thank Anastasia Suraev for her assistance with participant randomisation.

\section{Authors' contributions}

AS, Cl, AJC, BD, NAJ, MH, PSH, ISM and DM contributed to the study conception and design. Data collection was performed by AS, AS and DM. Blood sample analyses were conducted by PTD, RCK and AJC. Data analysis was performed by AS and DM. Results of the experiment were interpreted by AS, CI, PTD, RCK, AJC, BD, NAJ, AS, ISM and DM. The first draft of the manuscript was written by AS and DM, and all authors contributed to previous versions of the manuscript. All authors read and approved the final manuscript.

\section{Funding}

This research project was funded by the Lambert Initiative for Cannabinoid Therapeutics, a philanthropically funded centre for medicinal cannabis research at the University of Sydney.

\section{Availability of data and materials}

The datasets generated during and/or analysed during the current study are available from the corresponding author on reasonable request. 


\section{Declarations}

\section{Ethics approval and consent to participate}

This investigation was approved by the Sydney Local Health District's Human Research Ethics Committee (2020/ETH00226), registered with the Australia and New Zealand Clinical Trials Registry (ACTRN12620000941965) and conducted in accordance with Good Clinical Practice guidelines, the Declaration of Helsinki (1983) and local regulations. Participants provided written informed consent prior to participation in the trial.

\section{Consent for publication}

Not applicable.

\section{Competing interests}

P.T.D., R.C.K. I.S.M. and D.M receive salary support from the Lambert Initiative for Cannabinoid Therapeutics. I.S.M. also acts as a consultant to Kinoxis Therapeutics and an advisor to Psylo and Emyria and is an inventor on several patents relating to novel cannabinoid therapeutics, none of which relate to sports physiology or medicine. A.S., C.I., A.J.C., N.L., B.D., N.A.J., A.S., M.H. and P.H. have no conflicts of interest to disclose.

\section{Author details}

'Lambert Initiative for Cannabinoid Therapeutics, The University of Sydney, Sydney, NSW, Australia. ${ }^{2}$ Brain and Mind Centre, The University of Sydney, Sydney, NSW, Australia. ${ }^{3}$ School of Psychology, Faculty of Science, The University of Sydney, Sydney, NSW, Australia. ${ }^{4}$ School of Health Sciences and Social Work, Griffith University, Gold Coast, QLD, Australia. ${ }^{5}$ Menzies Health Institute Queensland, Gold Coast, QLD, Australia. ${ }^{6}$ School of Medical Science, Griffith University, Gold Coast, QLD, Australia. ${ }^{7}$ South West Clinical School, University of New South Wales, Sydney, NSW, Australia. ${ }^{8}$ Ingham Institute of Applied Medical Research, Sydney, NSW, Australia. ${ }^{9}$ Faculty of Medicine and Health, The University of Sydney, Sydney, NSW, Australia. ${ }^{10}$ NICM Health Research Institute, Western Sydney University, Sydney, NSW, Australia. ${ }^{11}$ Brisbane Sport and Exercise Medicine Specialists, Brisbane, QLD, Australia. ${ }^{12}$ Royal Prince Alfred Hospital, Sydney, NSW, Australia.

\section{Received: 2 November 2021 Accepted: 1 February 2022}

Published online: 02 March 2022

\section{References}

1. Noreen N, Muhammad F, Akhtar B, Azam F, Anwar MI. Is Cannabidio a promising substance for new drug development? A review of its potential therapeutic applications. Crit Rev Eukaryot Gene Expr. 2018;28:73-86.

2. Thiele EA, Marsh ED, French JA, Mazurkiewicz-Beldzinska M, Benbadis SR, Joshi C, Lyons PD, Taylor A, Roberts C, Sommerville K, Group GS. Cannabidiol in patients with seizures associated with Lennox-Gastaut syndrome (GWPCARE4): A randomised, double-blind, placebo-controlled phase 3 trial. Lancet (London, England). 2018;391:1085-96.

3. Devinsky O, Cross JH, Laux L, Marsh E, Miller I, Nabbout R, Scheffer IE, Thiele EA, Wright S. Trial of Cannabidiol for drug-resistant seizures in the Dravet syndrome. N Engl J Med. 2017;376:2011-20.

4. Devinsky O, Patel AD, Cross JH, Villanueva V, Wirrell EC, Privitera M, Greenwood SM, Roberts C, Checketts D, VanLandingham KE, Zuberi SM. Effect of Cannabidiol on drop seizures in the Lennox-Gastaut syndrome. N Engl J Med. 2018;378:1888-97.

5. U.S. Food and Drug Administration Center for Drug Evaluation and Research. Epidiolex NDA 210365 Approval Letter. 2018. https://www. accessdata.fda.gov/drugsatfda_docs/nda/2018/210365Orig1s000Approv. pdf. 30th March 2021.

6. Linares IM, Zuardi AW, Pereira LC, Queiroz RH, Mechoulam R, Guimaraes FS, Crippa JA. Cannabidiol presents an inverted U-shaped dose-response curve in a simulated public speaking test. Braz J Psychiatry. 2019;41:9-14.

7. Zuardi AW, Crippa JAS, Hallak JEC, Gorayeb R. Human experimental anxiety: actual public speaking induces more intense physiological responses than simulated public speaking. Rev Bras Psiquiatr. 2013;35:248-53.

8. Leweke FM, Piomelli D, Pahlisch F, Muhl D, Gerth CW, Hoyer C, Klosterkötter J, Hellmich M, Koethe D. Cannabidiol enhances anandamide signaling and alleviates psychotic symptoms of schizophrenia. Transl Psychiatry. 2012;2:e94.

9. McGuire P, Robson P, Cubala WJ, Vasile D, Morrison PD, Barron R, Taylor A, Wright S. Cannabidiol (CBD) as an adjunctive therapy in schizophrenia: a multicenter randomized controlled trial. Am J Psychiatry. 2018;175:225-31

10. Millar SA, Stone NL, Yates AS, Sullivan SE. A systematic review on the pharmacokinetics of Cannabidiol in humans. Front Pharmacol. 2018. https://doi.org/10.3389/fphar.2018.01365.

11. Larsen C, Shahinas J. Dosage, efficacy and safety of Cannabidiol administration in adults: a systematic review of human trials. J Clin Med Res. 2020:12:129-41.

12. Taylor L, Gidal B, Blakey G, Tayo B, Morrison G. A phase I, randomized, double-blind, placebo-controlled, single ascending dose, multiple dose, and food effect trial of the safety, tolerability and pharmacokinetics of highly purified Cannabidiol in healthy subjects. CNS Drugs. 2018;32:1053-67.

13. Arnold JC, Nation T, McGregor IS. Prescribing medicinal cannabis. Aust Prescr. 2020:43:152-9

14. Zuardi AW. Cannabidiol: from an inactive cannabinoid to a drug with wide spectrum of action. Rev Bras Psiquiatr. 2008:30:271-80.

15. Leas EC, Nobles AL, Caputi TL, Dredze M, Smith DM, Ayers JW. Trends in Internet searches for Cannabidiol (CBD) in the United States. JAMA Netw Open. 2019;2:e1913853.

16. Kasper AM, Sparks SA, Hooks M, Skeer M, Webb B, Nia H, Morton JP, Close GL. High prevalence of Cannabidiol use within male professional Rugby Union and League Players: a quest for pain relief and enhanced recovery. Int J Sport Nutr Exerc Metab. 2020;30:1-8.

17. McGregor IS, Cairns EA, Abelev S, Cohen R, Henderson M, Couch D, Arnold JC, Gauld N. Access to cannabidiol without a prescription: a crosscountry comparison and analysis. Int J Drug Policy. 2020;85:102935.

18. World Anti Doping Agency. Summary of major modifications and explanatory notes. 2018. https://www.wada-ama.org/sites/default/files/ prohibited list 2018_summary_of modifications_en.pdf. 30 March 2021.

19. Cochrane-Snyman KC, Cruz C, Morales J, Coles M. The effects of Cannabidiol oil on noninvasive measures of muscle damage in men. Med Sci Sports Exerc. 2021;53:1460-772.

20. Isenmann E, Veit S, Starke L, Flenker U, Diel P. Effects of Cannabidiol supplementation on skeletal muscle regeneration after intensive resistance training. Nutrients. 2021;13:3028.

21. McCartney D, Benson MJ, Desbrow B, Irwin C, Suraev A, McGregor IS. Cannabidiol and sports performance: a narrative review of relevant evidence and recommendations for future research. Sports Med Open. 2020;6:27.

22. Ibeas Bih C, Chen T, Nunn AV, Bazelot M, Dallas M, Whalley BJ. Molecular targets of Cannabidiol in neurological disorders. Neurotherapeutics. 2015:12:699-730

23. Lee EC, Whitehead AL, Jacques RM, Julious SA. The statistical interpretation of pilot trials: should significance thresholds be reconsidered? BMC Med Res Methodol. 2014:14:41.

24. Birnbaum AK, Karanam A, Marino SE, Barkley CM, Remmel RP, Roslawski M, Gramling-Aden M, Leppik IE. Food effect on pharmacokinetics of cannabidiol oral capsules in adult patients with refractory epilepsy. Epilepsia. 2019:60:1586-92

25. Lakens D. Sample size justification. PsyArXiv. 2021.

26. Armstrong LE, Pumerantz AC, Fiala KA, Roti MW, Kavouras SA, Casa DJ, Maresh CM. Human hydration indices: acute and longitudinal reference values. Int J Sport Nutr Exerc Metab. 2010;20:145-53.

27. Suraev A, Grunstein RR, Marshall NS, D'Rozario AL, Gordon CJ, Bartlett DJ, Wong K, Yee BJ, Vandrey R, Irwin C, Arnold JC, McGregor IS, Hoyos CM. Cannabidiol (CBD) and $\triangle 9$-tetrahydrocannabinol (THC) for chronic insomnia disorder ('CANSLEEP'trial): protocol for a randomised, placebo-controlled double-blinded, proof-of-concept trial. BMJ Open. 2020;10:e034421.

28. Coyle E, González-Alonso J. Cardiovascular drift during prolonged exercise: new perspectives. Exerc Sport Sci Rev. 2001;29:88-92.

29. Borg G. Borg's perceived exertion and pain scales. Champaign: Human Kinetics; 1998. p. viii-104- viii.

30. Hardy CJ, Rejeski WJ. Not what, but how one feels: the measurement of affect during exercise. J Sport Exerc Psychol. 1989;11:304-17.

31. Griffin SE, Robergs RA, Heyward VH. Blood pressure measurement during exercise: a review. Med Sci Sports Exerc. 1997;29:149-59. 
32. Marteau TM, Bekker $\mathrm{H}$. The development of a six-item short-form of the state scale of the Spielberger State-Trait Anxiety Inventory (STAI). Br J Clin Psychol. 1992;31:301-6.

33. Shacham S. A shortened version of the Profile of Mood States. J Pers Assess. 1983;47:305-6.

34. Kevin RC, Vogel R, Doohan P, Berger M, Amminger GP, McGregor IS. A validated method for the simultaneous quantification of CBD, THC, and their metabolites in human plasma, and application to plasma samples from an oral CBD open label trial. Drug Test Anal. 2020;13:614-27.

35. Lakens D. Calculating and reporting effect sizes to facilitate cumulative science: a practical primer for t-tests and ANOVAs. Front Psychol. 2013. https://doi.org/10.3389/fpsyg.2013.00863.

36. Goulet-Pelletier JC, Cousineau D. A review of effect sizes and their confidence intervals, Part I: The Cohen's d family. Quant Methods Psychol. 2018;14:242-65.

37. Borenstein MH, Higgins LV, Julian PT, Rothstein HR. Introduction to metaanalysis. West Sussex: Wiley; 2009.

38. Goulet-Pelletier JC, Cousineau D. Corrigendum to "A review of effect sizes and their confidence intervals, part l: the Cohen's d family". Quant Methods Psychol. 2018;15:54-54.

39. Cohen J. Statistical power analysis for the behavioural sciences. New York: Routledge; 1988

40. Burke LM, Whitfield J, Heikura IA, Ross MLR, Tee N, Forbes SF, Hall R, McKay AKA, Wallett AM, Sharma AP. Adaptation to a low carbohydrate high fat diet is rapid but impairs endurance exercise metabolism and performance despite enhanced glycogen availability. J Physiol. 2020;599:771-90.

41. Pawlak-Chaouch M, Boissiere J, Gamelin FX, Cuvelier G, Berthoin S, Aucouturier J. Effect of dietary nitrate supplementation on metabolic rate during rest and exercise in human: a systematic review and a metaanalysis. Nitric Oxide. 2016;53:65-76.

42. Frayn KN. Calculation of substrate oxidation rates in vivo from gaseous exchange. J Appl Physiol Respir Environ Exerc Physiol. 1983;55:628-34.

43. Nalbandian M, Radak Z, Taniguchi J, Masaki T. How different respiratory rate patterns affect cardiorespiratory variables and performance. Int J Exerc Sci. 2017;10:322-9.

44. Conley KE, Jubrias SA, Cress ME, Esselman P. Exercise efficiency is reduced by mitochondrial uncoupling in the elderly. Exp Physiol. 2013;98:768-77.

45. Conley KE, Jubrias SA, Cress ME, Esselman PC. Elevated energy coupling and aerobic capacity improves exercise performance in endurancetrained elderly subjects. Exp Physiol. 2013;98:899-907.

46. Hao E, Mukhopadhyay P, Cao Z, Erdelyi K, Holovac E, Liaudet L, Lee WS, Hasko G, Mechoulam R, Pacher P. Cannabidiol protects against doxorubicin-induced cardiomyopathy by modulating mitochondrial function and biogenesis. Mol Med. 2015;21:38-45.

47. Mukhopadhyay P, Rajesh M, Horvath B, Batkai S, Park O, Tanchian G, Gao RY, Patel V, Wink DA, Liaudet L, Hasko G, Mechoulam R, Pacher P. Cannabidiol protects against hepatic ischemia/reperfusion injury by attenuating inflammatory signaling and response, oxidative/nitrative stress, and cell death. Free Radic Biol Med. 2011;50:1368-81.

48. Valvassori SS, Bavaresco DV, Scaini G, Varela RB, Streck EL, Chagas MH, Hallak JEC, Zuardi AW, Crippa JA, Quevedo J. Acute and chronic administration of cannabidiol increases mitochondrial complex and creatine kinase activity in the rat brain. Rev Bras Psiquiatr. 2013;35:380-6.

49. da Silva VK, de Freitas BS, Dornelles VC, Kist LW, Bogo MR, Silva MC, Streck EL, Hallak JE, Zuardi AW, Crippa JAS, Schroder N. Novel insights into mitochondrial molecular targets of iron-induced neurodegeneration: reversal by cannabidiol. Brain Res Bull. 2018;139:1-8.

50. Fišar Z, Singh N, Hroudová J. Cannabinoid-induced changes in respiration of brain mitochondria. Toxicol Lett. 2014;231:62-71.

51. Rimmerman N, Ben-Hail D, Porat Z, Juknat A, Kozela E, Daniels MP, Connelly PS, Leishman E, Bradshaw HB, Shoshan-Barmatz V, Vogel Z. Direct modulation of the outer mitochondrial membrane channel, voltagedependent anion channel 1 (VDAC1) by cannabidiol: a novel mechanism for cannabinoid-induced cell death. Cell Death Dis. 2013;4:e949.

52. Schultze N, Wanka H, Zwicker P, Lindequist U, Haertel B. Mitochondrial functions of THP-1 monocytes following the exposure to selected natural compounds. Toxicology. 2017;377:57-63.

53. Singh N, Hroudová J, Fišar Z. Cannabinoid-induced changes in the activity of electron transport chain complexes of brain mitochondria. J Mol Neurosci. 2015;56:926-31.
54. Wu HY, Huang CH, Lin YH, Wang CC, Jan TR. Cannabidiol induced apoptosis in human monocytes through mitochondrial permeability transition pore-mediated ROS production. Free Radic Biol Med. 2018;124:311-8.

55. Richards JC, Crecelius AR, Larson DG, Dinenno FA. Acute ascorbic acid ingestion increases skeletal muscle blood flow and oxygen consumption via local vasodilation during graded handgrip exercise in older adults. Am J Physiol Heart Circ Physiol. 2015;309:H360-8.

56. Richards JC, Racine ML, Hearon CM, Kunkel M, Luckasen GJ, Larson DG, Allen JD, Dinenno FA. Acute ingestion of dietary nitrate increases muscle blood flow via local vasodilation during handgrip exercise in young adults. Physiol Rep. 2018;6:12.

57. Stanley CP, Wheal AJ, Randall MD, O'Sullivan SE. Cannabinoids alter endothelial function in the Zucker rat model of type 2 diabetes. Eur J Pharmacol. 2013;720:376-82.

58. Wheal AJ, Cipriano M, Fowler CJ, Randall MD, O'Sullivan SE. Cannabidiol improves vasorelaxation in Zucker diabetic fatty rats through cyclooxygenase activation. J Pharmacol Exp Ther. 2014;351:457-66.

59. Wheal AJ, Jadoon K, Randall MD, O'Sullivan SE. In vivo Cannabidiol treatment improves endothelium-dependent vasorelaxation in mesenteric arteries of Zucker diabetic fatty rats. Front Pharmacol. 2017. https://doi. org/10.3389/fphar.2017.00248.

60. Stanley CP, Hind WH, Tufarelli C, O'Sullivan SE. Cannabidiol causes endothelium-dependent vasorelaxation of human mesenteric arteries via CB1 activation. Cardiovasc Res. 2015;107:568-78.

61. Jadoon KA, Tan GD, O'Sullivan SE. A single dose of cannabidiol reduces blood pressure in healthy volunteers in a randomized crossover study. JCI Insight. 2017;2:e93760.

62. Baden DA, McLean TL, Tucker R, Noakes TD, Gibson AS. Effect of anticipation during unknown or unexpected exercise duration on rating of perceived exertion, affect, and physiological function. Br J Sports Med. 2005;39:742-6.

63. Argueta DA, Ventura CM, Kiven S, Sagi V, Gupta K. A balanced approach for Cannabidiol use in chronic pain. Front Pharmacol. 2020. https://doi. org/10.3389/fphar.2020.00561.

64. Burstein S. Cannabidiol (CBD) and its analogs: a review of their effects on inflammation. Bioorg Med Chem. 2015;23:1377-85.

65. Gyires K, Zádori ZS. Role of Cannabinoids in gastrointestinal mucosal defense and inflammation. Curr Neuropharmacol. 2016;14:935-51.

66. Hanlon EC. Impact of circadian rhythmicity and sleep restriction on circulating endocannabinoid (eCB) N-arachidonoylethanolamine (anandamide). Psychoneuroendocrinology. 2020;111:104471.

67. Raichlen DA, Foster AD, Gerdeman GL, Seillier A, Giuffrida A. Wired to run: exercise-induced endocannabinoid signaling in humans and cursorial mammals with implications for the "runner's high." J Exp Biol. 2012;215:1331-6.

68. Raichlen DA, Foster AD, Seillier A, Giuffrida A, Gerdeman GL. Exerciseinduced endocannabinoid signaling is modulated by intensity. Eur J Appl Physiol. 2013;113:869-75.

69. Hillard CJ. Circulating endocannabinoids: from whence do they come and where are they going? Neuropsychopharmacology. 2018;43:155-72.

70. Zderic TW, Coggan AR, Ruby BC. Glucose kinetics and substrate oxidation during exercise in the follicular and luteal phases. J Appl Physiol. 2001;90:447-53.

\section{Publisher's Note}

Springer Nature remains neutral with regard to jurisdictional claims in published maps and institutional affiliations. 